\title{
DESIGNING PEPTIDOMIMETICS
}

\author{
Juan J. Perez \\ Dept. of Chemical Engineering \\ ETS d'Enginyeria Industrial
}

Av. Diagonal, 647

08028 Barcelona, Spain 


\section{Abstract}

The concept of a peptidomimetic was coined about forty years ago. Since then, an enormous effort and interest has been devoted to mimic the properties of peptides with small molecules or pseudopeptides. The present report aims to review different approaches described in the past to succeed in this goal. Basically, there are two different approaches to design peptidomimetics: a medicinal chemistry approach, where parts of the peptide are successively replaced by non-peptide moieties until getting a non-peptide molecule and a biophysical approach, where a hypothesis of the bioactive form of the peptide is sketched and peptidomimetics are designed based on hanging the appropriate chemical moieties on diverse scaffolds. Although both approaches have been used in the past, the former has been more widely used to design peptidomimetics of secretory peptides, whereas the latter is nowadays getting momentum with the recent interest in designing protein-protein interaction inhibitors. The present report summarizes the relevance of the information gathered from structure-activity studies, together with a short review on the strategies used to design new peptide analogs and surrogates. In a following section there is a short discussion on the characterization of the bioactive conformation of a peptide, to continue describing the process of designing conformationally constrained analogs producing first and second generation peptidomimetics. Finally, there is a section devoted to review the use of organic scaffolds to design peptidomimetics based on the information available on the bioactive conformation of the peptide. 


\section{Introduction}

Peptides are not only important mediators in the regulation of many physiological processes eliciting actions as hormones, neurotransmitters, neuromodulating agents or immunomodulators, but also can act as antagonists, enzyme inhibitors or protein-protein disruptors, blocking the transduction of diverse signals. This wide spectrum of activities makes peptides attractive molecules for pharmaceutical intervention. Despite the plethora of pharmacological actions exhibited, only a small number of peptides are currently in the market due to their poor oral bioavailability, low absorption, rapid degradation by proteolytic enzymes and immunogenic profile [1]. This poor pharmacokinetic profile requires their nasal or parenteral administration.

Most peptides presently approved for therapeutical intervention are agonists, being used in substitution therapy with well-known examples like oxytocin for inducing or augment labor; parathynoid hormone for the treatment of osteoporosis; luteinizing hormone releasing hormone for the treatment for infertility; the segment 17-36 of the glucagon-like peptide- 1 for the treatment of diabetes; peginesatide an erythropoietin peptide surrogate for the treatment of anemia associated with chronic kidney disease; somatostatin used in acromegaly and neuroendocrine tumor therapy; gastrin-releasing peptide used for cancer treatment or calcitonin for the treatment of osteoporosis [2]. In contrast, the number of peptide analogs used as blocking agents is much lower. There are a few antagonists like icatibant, a bradykinin B2 antagonist used for the symptomatic treatment of acute attacks of hereditary angioedema in adults with C1-esterase-inhibitor deficiency [3] or saralasin, an angiotensin II antagonist used for the treatment of hypertension [4]. There are also a few peptide analogs used as enzyme inhibitors like enapril, an inhibitor of the angiotensin converting enzyme used as antihypertensive drug [5] or bivalirudin, a hirudin analog inhibitor of thrombin used as an anticoagulant in patients with unstable angina undergoing percutaneous transluminal coronary angioplasty [6]. Finally, there are only a few peptide analogs in the market acting as protein-protein disruptors, like cyclosporin A an immunosuppressant drug used in organ transplantation to prevent rejection [7] or the antiviral enfuvirtide, a segment of the transmembrane protein gp41 of the HIV that inhibits fusion of the viral envelope and host cell membrane [8]. In addition, there is a large number of promising molecules in this group of peptides presently under development like the series of peptide analogs containing the RGD recognition motif with antithrombotic profile [9] or, the recently developed series of Bak-BH3 analogs, compounds that enhance apoptosis through the inhibition of the Bcl-XL protein and used as anticancer drugs [10].

Two major approaches have been used in the past to surmount the poor pharmacokinetic profile of peptides. One consists in the use of pseudopeptides [11, 12] and cyclic analogs [13] designed to be resistant to proteolytic degradation and endowed with improved bioavailability. Recent advances in this area along with the development of new delivery procedures [14] make this approach very promising [15]. The other approach consists of designing small molecules -so called peptidomimetics- that mimic the steric and chemical features of bioactive peptides. The procedure to design peptidomimetics is not unique 
and there are diverse strategies described in the literature that combine medicinal chemistry and modeling methodologies in different proportions. The focus of the present review is to provide a brief summary of the diverse strategies described in the literature devoted to design peptidomimetics. The reader is also invited to review previous reports published in the literature on the topic [16-29].

The concept of peptidomimetic was coined about forty years ago when the long time postulated endogenous opioid enkephalin was discovered in the middle of the seventies (actually two different enkephalin analogs were isolated: Met-enkephalin and Leu-enkephalin with a similar pharmacological profile) [30]. The existence of enkephalins had been long time postulated as an explanation for the known pharmacological actions of morphine. The characterization of the enkephalins provided for the first time the opportunity to compare a peptide sequence with the chemical structure of the small molecule exerting the same pharmacological action. Indeed, comparison of the two structures led to the identification of specific common steric and chemical features that were assumed to be requirements for the $\mu$-opioid receptor activation, boosting the concept that the biological action of morphine was due to its ability to mimic the bound conformation of enkephalin [31]. This opened the door to the fascinating area of peptidomimetic research full of successful stories.

Peptidomimetic design requires as first step the establishment of solid structure-activity relationships that permits the identification of those residues important for peptide recognition and activation. This involves knowledge of the minimum peptide length that preserves biological activity, together with a list of peptide analogs with known biological activity. To construct this list, analogs can be designed by modification of the peptide backbone or by side chain replacement. Once a solid structureactivity relationships is established, the design of a peptidomimetic requires specific knowledge about the features of the bioactive conformation that can be inferred either from spectroscopic analysis and/or computational methods. These two sources of information provide the grounds to produce a first generation of peptidomimetics. For this purpose two different approaches can be followed, as displayed in Figure 1. The first is a medicinal chemistry approach that involves the synthesis of conformationally constrained analogs aiming at mimicking the features of the bound conformation. This is carried out either through the synthesis of diverse analogs incorporating conformationally constrained amino acids in different positions or through the synthesis of analogs that incorporate organic scaffolds replacing two consecutive residues. First generation peptidomimetics are hybrid molecules that are in part peptide and in part small molecule with improved pharmacokinetic properties in regard to the parent peptide. After evaluation of their biological activity they are used as the starting point to develop second generation peptidomimetics, i.e. small molecule-like compounds. Combinatorial chemistry can be a helpful strategy to be used at this step. Alternatively, peptidomimetic design can be performed involving the use of computational chemistry tools used to sketch features of the bioactive conformation [32]. These studies combined with the information gathered from structure-activity relationships studies can be used to develop a pharmacophore defining the steric and electronic features necessary to ensure the optimal supramolecular interactions with the target macromolecule [33]. The pharmacophoric hypothesis can be 
subsequently used as a query in virtual screening to search for hits in diverse data bases [34]. Alternatively, it can also be used as a template to design new molecules that fulfill the pharmacophoric hypothesis using diverse chemical scaffolds.

\section{Structure-Activity Relationships Studies}

It is a well-established paradigm in chemistry that the physicochemical properties of molecules as well as their biological activities are related to their structure. Advances in understanding the connection between structure and physicochemical properties or biological activity of molecules have always gone hand in hand, stressing their intrinsic connection [35]. The establishment of structure-activity relationships in peptides requires an understanding of the importance of the $\mathrm{N}$ - and $\mathrm{C}$-terminal groups for activity; the minimum peptide segment preserving function and identification of specific residues responsible for conferring biological activity to the peptide. Actually, there are a number of naturally occurring peptides that see their activity modified upon modifications of the terminal groups. Thus for example, C-terminus amidation is a common posttranslational modification that can be key for the activity of a peptide. For example, the C-terminus of substance P needs to be amidated to exhibit activity [36]. Another important piece of information regards the shortest fragment of the peptide retaining biological function. Indeed, since peptides are large molecules, they may interact with a receptor through diverse anchoring points. Knowledge of the shortest fragment retaining biological function is important to set boundaries for designing a mimetic. There are diverse examples of bioactive peptides where a specific biological activity is associated to a short fragment. Thus, for example the sequence of Met-enkephalin (Tyr-Gly-Gly-PheMet) is the shortest sequence within the family of opioid peptides retaining full activity and corresponds to the five residue $\mathrm{N}$-terminal end of $\beta$-endorphin, a larger endogenous opioid [37]. Similarly, the four residue C-terminal segment of cholecystokinin known as CCK-4 (Trp-Met-Asp-PheNH $\mathrm{N}_{2}$ ), represents the shortest fragment of the native peptide retaining full activity [38].

Once the smallest active fragment is identified and peptide termini characterized, it is necessary to identify what residues are key for peptide activity. For this purpose a series of analogs are synthesized and their biological activity tested. Analogs produced at this step are the result of conservative changes. One procedure to follow consists of testing the effect of deleting one or more consecutive amino acid(s) or even a combinatorial deletion of two or more positions throughout the sequence. Similarly, analogs produced by changing the order of two residues in the sequence sometimes provide information about the importance of a specific side chain. Another procedure utilized consists of replacing a residue by its $D$ amino acid enantiomer, providing information about the importance of the stereochemical requirements of a residue side chain [39]. Alternatively, a systematic replacement by alanine in each of the residues of the polypeptide chain is also a standard procedure to gather information about the role played by the diverse residues on the activity of the peptide [40]. Alanine substitutions are not expected to change dramatically the intrinsic conformational features of the polypeptide chain, but can provide information about how the diverse nature of the side chains is involved in receptor recognition. Table 1 shows as an example the 


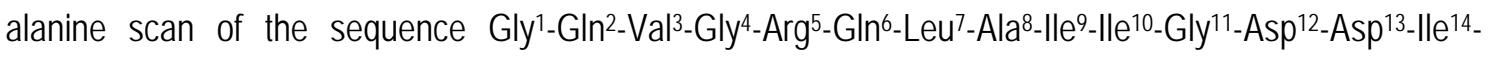
$A s n^{15}-\mathrm{Arg}^{16}$, an inhibitor of the protein $\mathrm{Bcl}-\mathrm{X}_{\mathrm{L}}$ that is involved in the apoptosis process [41]. As it can be seen, most of the replacements produce a remarkable effect on the affinity of the ligand, being at Leu ${ }^{7}$ the replacement that produces the most dramatic effect. In contrast, replacement of residues $1 e^{9}$, Gly ${ }^{11}$ and Asp ${ }^{13}$ does not produce a significant change in the affinity of the ligand. Actually, the NMR structure of the peptide bound to $\mathrm{BCl}-\mathrm{X}_{\mathrm{L}}$ provides an explanation to this result since these residues are solvent exposed [41]. The alanine scan provides information about the relative importance of the diverse residues in the sequence for affinity and activity that can be used as guide for the synthesis of new analogs.

In a subsequent step, new peptide analogs can be designed modifying the peptide backbone or through side chain replacement. Biological evaluation of these analogs may provide information on the relevance of specific residues and reveals information about the features of the peptide-receptor recognition interface. However, it should be borne in mind that modifications on the peptide structure may also alter its conformational profile, impairing its ability to attain the bioactive conformation. Modifications of the peptide backbone include N-methylation of the nitrogen amide 1 in Figure 2 [42] and reduction of the peptide bond producing methylene amino derivatives 2 in Figure 2 [43]. Both procedures produce peptide analogs with a reduced capability to undertake hydrogen bond interactions. Moreover, partial or total removal of the hydrogen bond capabilities of the peptide bond also reduces hydration making the compounds more suited to membrane penetration. Actually, reduction of the peptide bond is a specific case of a more general class of modifications known as isosteric replacements, where the peptide bond is substituted by an equivalent chemical group, as will be discussed later [44]. Alternatively, production of analogs designed by side chain replacement provides insights into the kind of interaction the side chain is involved with its receptor. For example, replacement of a tyrosine by a phenylalanine provides information about the role of the hydroxyl group of the phenyl moiety, whereas replacement by a hydrophobic residue like leucine by phenylalanine provides information about the requirement of an aromatic moiety at this position.

\section{Peptide Bond Isosteric Replacement}

Biosiosteric replacement represents a rational approach for the modification of lead compounds into safer and more clinically effective agents. The procedure provides a guide to design new analogs of a given compound through substitution of specific chemical moieties by other functional groups (isosteres) that have chemical and physical similarities producing broadly similar biological effects [45].

According to the original definition by Langmuir [46], isosteres are atoms, ions and molecules that have identical valence electrons and expected to exhibit similar physicochemical properties. Thus for example, the sodium ion $\left(\mathrm{Na}^{+}\right)$and the hydrogen ion $\left(\mathrm{H}^{+}\right)$, are isosteric ions with no valence electron left or, carbon dioxide $\left(\mathrm{CO}_{2}\right)$ and nitrous oxide $\left(\mathrm{N}_{2} \mathrm{O}\right)$ are isosteres both with sixteen valence electrons. This definition was extended later to include molecules and chemical moieties molecules in which the peripheral layer of electrons can be considered identical. So, for example methyl, amine and hydroxyl 
groups are isoteres since the three groups exhibit seven valence electrons. The concept of isosterism was broadened a few years later to include chemical groups that possess near-equal molecular shapes and volumes, approximately the same distribution of electrons, and which exhibit similar physical properties [47].

Peptide bond isosteric replacement is a procedure aimed at designing peptide analogs close to the parent peptide endowed with improved resistance to proteolytic cleavage through peptide bond replacement using peptide bond surrogates. However, caution should be exercised since these modifications affect the chemical features of the peptide bond and moreover, they may also influence the conformational profile of the peptide and consequently, its affinity. This procedure has been demonstrated in the past to be good strategy to design first generation peptidomimetics and, especially suitable in designing protease inhibitors. Specifically, in this case since the bioactive conformation is mostly extended a simple isostere replacement of the scissile bond usually provides an active compound, although not necessarily with higher affinity than the original peptide. A recent story of successful use of isostere replacement as strategy for drug design can be found in the publications that led to the design of a first generation of HIV protease inhibitors [48].

Figure 2 shows the chemical structures of typical peptide bond isosteres. A conservative replacement of the amide peptide bond consists of the substitution of the carbonyl oxygen by a sulfur atom to yield a thioamide isostere 3 (Figure 2). The substitution of oxygen to sulfur increases the rotational barrier around the peptide bond by 2-3 kcal/mole, making these analogs good inhibitors of peptidylprolyl isomerases, enzymes that catalyze the rotation across the peptide bond. On the other hand, this isostere exhibits a higher dipole moment than the corresponding amides and consequently, it is a suitable substitution to incorporate in helical structures, although the sulfur atom of thioamides is a poor hydrogenbond acceptor [49]. In medicinal chemistry, thioamide analogs of antibiotic peptides represent a successful example of the potential use of this isostere in the design of peptidomimetics [50].

The replacement of the peptide amide nitrogen by oxygen or sulfur generates an ester 4 (Figure 2) and a thionoester isosteres 5 (Figure 2), respectively. In this case, although rotational barriers are lower compared to those of the amides, electron delocalization provides a partial double bond character to the ester bond so that both, cis and trans conformations are attainable [51]. From the structural point of view, esters exhibit higher torsional flexibility than amides and moreover, they are deprived of the hydrogen bond capability as donors, with an accepting hydrogen bond capability of the carbonyl group weaker than in the case of the amide group. All this, together with the fact that they are vulnerable to hydrolysis makes them less attractive for peptidomimetic design. Peptides that have at least an ester link between two amino acids are referred as depsipeptides. In fact, there is a number of naturally occurring cylic depsipeptides with a variety of pharmacological profiles, like actinomycin that exhibits antibiotic activity [52] or romidepsin with a cytotoxic profile currently undergoing clinical trial as anticancer drug for the treatment of cutaneous T-cell lymphoma and peripheral T-cell lymphoma [53]. 
Replacement of the nitrogen by a carbon produces a ketomethylene isostere 6 (Figure 2). In this case the cis/trans constraint associated to the peptide bond is lifted. The ketomethylene isostere has been successfully used to design renin [54] and HIV protease inhibitors [55]. Moreover, its alpha carbon can be substituted further by a fluor, producing $\alpha$-fluoroketone isosteres 7 (Figure 2). These isosteres contain fluorine-activated electrophilic carbonyl groups that react readily with active site nucleophiles such as hydroxyl groups in serine proteases, thiol groups in cysteine proteases or, water in aspartate and metalloproteases to produce transition-state analogues in the active site [56].

Alternatively, the carbonyl group can be replaced by similar chemical groups using other heteroatoms, like sulfur in the case of the sulfonamide $\mathbf{8}$ (Figure 2), sulfonate $\mathbf{9}$ (Figure 2) or phosphorous in the case of phosphonamide 10 (Figure 2), phosphonate 11 (Figure 2), phosphothionate 12 (Figure 2) or phosphinate 13 (Figure 2). These isosteres exhibit a tetrahedral configuration making them suitable to act as transition state analogs. Considering their structures, sulfonamides and sulfonates produce a significant twist in the backbone chain in comparison to the amide bond, due to the difference on dihedral angle adopted (from a $180^{\circ}$ of the amide bond to $a 0^{\circ}$ of the sulfonamide) necessary to preserve delocalization of $\pi$ electrons. The sulfonamide NH is relatively more acidic than that of the amide moiety, and thus is a strong hydrogen bond donor.

Another possibility to produce peptide bond isosteres is the reduction of the amide carbonyl to an alcohol. These isosteres can be considered as transition state analogs, since proteolysis occurs through a tetrahedral intermediate. If the nitrogen amide is preserved the isostere obtained is hydroxylamine 14 (Figure 2), and if the nitrogen is replaced by carbon we obtain hydroxyethylene 15 (Figure 2) and well as dihydroxylethylene 16 (Figure 2). For example, aliskiren is a potent inhibitor of renin for the treatment of hypertension is a hydroxyethylene isostere, substituted at the cleavage site [57].

Amide carbonyls can be further reduced to obtain methylene amino isosteres 2 (Figure 2) and derivatives, like the trifluoroethylamino isosteres 17 (Figure 2). These isosteres exhibit higher conformational flexibility due to the loss of the partial double character of the amide bond. The former compounds have been used in the development of agonists of cholecystokinin [58] and somatostatin [59] or antagonists of bombesin [60]. The latter compounds are interesting isosteres since the trifluoromethyl moiety is isopolar to the carbonyl group. Another interesting feature of these isosteres is the decreased basicity of the amine without compromising the ability of the $\mathrm{NH}$ to function as a $\mathrm{H}$-bond donor. The methyleneamino moiety has recently been used with success for designing inhibitors of Pin1, a peptidylprolyl isomerase involved in cis-trans isomerization of Xaa-Pro amide bonds [61]. Odanacatib, currently in phase III clinical trials is a nice example of analog containing a trifluoroethylamino isostere. This compound acts as an inhibitor of cathepsin $\mathrm{K}$, preventing calcium resorption to be used for the treatment of osteoporosis [62]. 
Substitution of the amine nitrogen by oxygen or sulfur produces derivatives like the methyleneoxy 18 (Figure 2) or the methylenemercapto 19 (Figure 2), respectively.

Alkanes can also be considered as isosteres of the peptide bond 20 (Figure 2). However, more interesting are when they are reduced to alkenes 21 (Figure 2) and their derivatives like fluoroalkenes 22 (Figure 2) and difluroalkenes $\mathbf{2 3}$ (Figure 2). These isosteres preserve the planarity of the peptide bond and the cis/trans isomerism associated. Alkenes are a better substitutes of the peptide bond, although exhibit smaller dipole moments and have lost their ability to participate in hydrogen bonding. These differences have consequences in the structural features of the peptide sequences they participate. Thus, for example they are expected to be helical structure disruptors. Moreover, the cis isomer in dipeptides Xaa-Pro is more stable, reducing their capability to participate in $\beta$-turns [63]. Examples of the use of this isostere can be found in diverse analogs of substance $P$ [64] or in the CXCR4 chemokine receptor antagonist FC131 [cyclo(-D-Tyr-Arg-Arg-Nal-Gly-), Nal = 3-(2-naphthyl)-alanine] [65]. Further reduction yields alkyne 24 (Figure 2) that can also be used as peptide bond isostere.

Other isosteres that recover the amide group at the expense of losing the alpha carbon are the hydrazine $\mathbf{2 5}$ (Figure 2) and the amideoxy 26 (Figure 2).

There are also cyclic isosteres that can be aromatic, although usually are partially or completely saturated rings. Typical cyclic isosteres include carbacycles 27 (Figure 2), azacycles 28 (Figure 2) and oxacycles 29 (Figure 2).

\section{Pseudopeptides}

This is a group of molecules designed to avoid protease degradation while preserving peptide sequence. Peptide analogs in this group include retro-inverso peptides, peptoids and $\beta$-peptides.

Retro-inverso peptide analogs consist of polypeptides in which the direction of one or more peptide bonds is reverted with a concomitant change of the configuration of the following alpha carbon of the polypeptide chain 30 (Figure 3) $[66,67]$. It can be distinguished between totally modified retro-inverso analogs when all the peptide bonds of the parent peptide are reversed and to partially modified retroinverso analogs when one or more peptide bonds are reversed. These compounds exhibit an improved resistance to proteolytic hydrolysis and in many cases, with retention of their biological activity. Due to their improved pharmacokinetic profile these peptide surrogates can be used as therapeutic agents. A recent example is the totally modified retro-inverso analog of the peptide OR2 that shows promising results for the treatment of Alzheimer's disease. OR2 is a decapeptide with sequence Asn-Arg-Gly-LysLeu-Val-Phe-Phe-Gly-Arg- $\mathrm{NH}_{2}$ with inhibitory activity against the aggregation of beta-amyloid. Aimed at finding peptide surrogates of OR2 with improved pharmacokinetic profile, the total retro-inverso analog RIOR2 was synthesized and proved to be as active as the template and highly stable to proteolysis [68]. Due 
to its pharmacological profile this analog will permit to pursue further experiments and demonstrate the efficacy of this therapy for the treatment of Alzheimer's disease.

Peptoids represent another variant to construct molecules using polypeptides as a source of inspiration with improved pharmacokinetic profile. Peptoids can be considered as polymers of $\mathrm{N}$ substituted glycines, so that they look like peptides but with the side chains attached to the backbone amide nitrogen instead to the $\alpha$-carbon 31 (Figure 3) $[69,70]$. The simplest member of the family is sarcosine (N-methylglycine), a naturally occurring amino acid found in muscles and other body tissues. From the pharmacological point of view, sarcosine is a competitive inhibitor of the type I glycine transporter and an N-methyl-D-aspartate receptor (NMDAR) co-agonist [71]. Peptoids exhibit an increased flexibility compared to regular peptides due to the achirality of the $\alpha$-carbon that provides a large range of allowable $\phi$ and $\psi$ angles and the presence of a tertiary amide bond since both the cis and trans conformations of the peptide bond are possible. These features may decrease the affinity of ligands compared to their parent peptides due to the entropic penalty paid upon binding to its receptor. Another structural feature of peptoids is their inability to form intramolecular hydrogen bonds through backbonebackbone interactions, because of the lack of amide hydrogens. Despite their limitations, peptoids can be driven to form helical secondary structures through a periodic incorporation of bulky, $\alpha$-chiral side chains. From the pharmacokinetic point of view, $\mathrm{N}$-alkylation, in particular methylation provides these molecules a reduced biodegradation profile since tertiary amides are more resistant to proteolytic degradation [72]. Moreover, they also exhibit increased bioavailability due to the lack of hydrogen donors favoring cell penetration. Accordingly, diverse peptoids with cell-penetrating properties and antimicrobial activities, as well as mimics of lung surfactant proteins have been reported [73]. Furthermore, ligands based on peptoids often containing a single $\alpha$-amino acid have been shown to have superior cell-penetrating abilities compared to the corresponding peptides [74].

A different strategy to construct pseudopeptides consists of using $\beta$-amino acids. These molecules are amino acids that have the amino group attached in beta position relative to the carbonyl group. There are two types of $\beta$-amino acids depending on the position of the side chain. When the side chain is attached to the carbon in alpha are called $\beta 232$ and $\beta 3$ when the side chain is attached to the carbon in beta 33 (Figure 3). Peptides constructed with these amino acids preserve all the chemical characteristics of natural peptides, but the addition of an extra methylene group to the backbone chain provides stability against peptidase degradation [75]. Moreover, analogs composed of alternating $\alpha$ - and $\beta$-amino acids residues are also very resistant toward degradation [76]. The only beta amino acids found in nature is beta-alanine, a component of the naturally occurring peptides carnosine and anserine, potent scavengers of reactive oxygen species as well as alpha-beta unsaturated aldehydes formed from peroxidation of cell membrane fatty acids during oxidative stress [77]. Although the addition of an extra methylene to the backbone chain adds certain flexibility to the molecule, $\beta$-peptides can adopt secondary structures like natural peptides $[78,79]$. Knowledge of the secondary structure trends shown by this kind of amino acids 
have been used to design amphipathic peptides that exhibit interesting properties as antibacterial agents [73].

\section{The Bioactive Conformation}

In addition to understand the chemical groups and peptide features important for activity as deduced from the structure-activity studies, knowledge of the features of the bioactive conformation is also necessary for designing peptidomimetics. The conformation attained by a flexible ligand when bound to its target macromolecule is known as the bioactive conformation. The binding process of a ligand to its target macromolecule is governed by the molecular interactions between the ligand and the residues involved in defining the binding site. At long distances electrostatic interactions are predominant, but at short distances the diverse contributions become comparable, so that the peptide finally adopts the conformation with the lowest energy within the environment of the target macromolecule. The affinity of a ligand for its target macromolecule $\mathrm{Ka}$ is related to the free energy of binding according to the relation $\Delta G^{0}=-R T I n K a$. The free energy has an enthalpic and an entropic contribution. The former contribution accounts for the favorable interactions between the peptide and the macromolecule, as well as for the energy penalty suffered by the peptide and/or the protein for not being in their lowest energy conformational state. On the other hand, the latter accounts for the loss of peptide configurational entropy upon binding to its target macromolecule [80]. It should also be taken into account a free energy associated to the desolvation/solvation process that includes both enthalpic and entropic contributions.

There are two limiting mechanisms to describe the ligand-protein recognition step. On the one hand, the conformational selection, also called population shift mechanism by which a peptide approaches in its bioactive conformation and fits into the binding site of the protein, like in the lock-and-the-key model [81]. On the other hand the induced fit mechanism, where the conformation of the peptide and the binding site of the protein simultaneously adapt to each other, like a glove to a hand [82]. However, there are indications suggesting that peptide binding may proceed through a combination of the two mechanisms. This idea has been explored in a recent report where a set of peptides with known bound conformation were docked into the corresponding target proteins using a mixed procedure that combines conformational selection and induced fit, achieving a $75 \%$ success rate in the prediction of the experimental results [83].

When the bioactive conformation is known, the mimicry process for designing peptidomimetics can be carried out by chemical group substitutions, restricted to preserve the overall geometry and taking into account the key residues for activity. Nowadays there are around 500 unique protein-peptide complexes determined by X-ray diffraction and NMR spectroscopy studies deposited in the protein data bank (pdb) [84] and compiled in the Pep-X data base [85]. Complexes include a few enzyme-inhibitor complexes, peptide-signaling proteins, antibody-antigen complexes and hormone-receptor complexes. Analysis of the structures of peptide-signaling proteins, as well as those of enzyme-peptide complexes with those of monomeric proteins, suggests that peptide ligands adopt conformations complementary to the tertiary structure of the binding domain. In other words, ligands adopt the conformation expected to attain as if 
they were a protein segment [86]. This finding opens the possibility to identify new linear regulatory motifs from the analysis of the 3D structure of the effector protein [87]. Moreover, peptide segments with the same sequence may adopt different secondary structures in diverse proteins like in the case of the segment NAAIRS that adopts a helical structure in phosphofructokinase and an extended conformation in thermolysin. Consequently, it is expected that the bound conformation of a peptide may be different for diverse target proteins.

Peptides can act as substrates of enzymes. The vast majority of peptides are substrates of proteases that catalyze the cleavage of a peptide bond very efficiently. There are two broad classes of proteases: those that use water as nucleophile to mediate the hydrolysis of the peptide bond, like aspartic and metalloproteases, and those that use the side chain of specific residues to produce the nucleophilic attack, like in serine, threonine and cysteine proteases, named after the residue involved. In this case, an acyl-enzyme intermediate is produced that is subsequently hydrolyzed by water to complete the hydrolysis process. Ligases represent another class of enzymes that use peptides as substrates. These enzymes attach a chemical moiety to the peptide chain mediating posttranslational modifications.

The catalytic efficiency of enzymes is due to their capability to stabilize the transition state, lowering the activation free energy of the reaction [88]. As a consequence enzymes are designed to have a high affinity for transition state analogs [89]. This strategy has been used for drug design constituting an ample class of peptidomimetics [90]. The efficiency of these enzymes achieved though evolution makes that the time necessary to study them using X-ray diffraction or NMR spectroscopy studies is much shorter than the time necessary to process the substrate. Accordingly, most of the complexes of peptide-enzyme are inhibitors, rather than substrates. Protease cleavage sites are frequently located in flexible solventexposed loops, although a number of sites have also been identified in a-helix structures. In general, enzyme binding sites are flexible regions, result that explains why only a few structures have been solved that include residues encompassing the cleavage site [91]. Inhibitors mostly bind in extended conformations like the HIV protease inhibitors (pbd entry 2FNT), although bent structures like the urokinase plasminogen activator inhibitor (entry 1GJB) can also be found. Some peptides exhibit a helical structure like calpain inhibitors (pdb entry 1NX1) and even hairpin structures like in the beta trypsin inhibitor (pdb entry 1SBW).

In the case of regulatory peptides, they adopt mostly an extended conformation and in a few cases helical structures. The trends observed in this class of peptides are the same those observed in enzymespeptide complexes. Thus for example, in the complex of the signaling Traf2 with a segment of CD40 (pdb entry $1 \mathrm{QSC}$ ) the peptide is found in an extended conformation, whereas in the complex of the antiapoptotic protein $\mathrm{Bcl}-\mathrm{xL}$ with a peptide of $\mathrm{BH} 3$ (pdb entry $3 \mathrm{FDL}$ ) the peptide is found in a a-helical conformation. 
Other important group of cell signaling peptide-protein complexes is those of short antigenic peptides bound to the major histocompatibilty complex (MHC) class I and II proteins that are subsequently presented to the appropriate T-cell receptors. In this case peptides appear in an extended conformation (pdb entry 1SYV) [92]. Similarly, peptides binding to the ATP-binding cassette transporter associated with antigen processing (TAP) bind in an extended kinked structure, analogous to those bound to MHC class I proteins [93].

In the case of antigen-antibody complexes, most of the structures reveal the antigen adopting a $\beta$ turn motif and deeply embedded in the antibody-antigen interface [94]. Interestingly, in this case the bound structures of the antigens do not necessarily correspond to those on the original epitope, since in most of the cases the anti-peptide antibodies do not bind to the native protein. Thus, for example in myohemerythrin the epitope of sequence EVVPHKK exhibits a helical structure [95], whereas when bound to the monoclonal antibody B1312 exhibits a type II $\beta$-turn [96].

In the case of hormones, some of the peptides are longer than 30 residues and adopt folded conformations, being the simplest the a-helix conformation [85]. Also within this group of peptides, the structure of [8-13]neurotensin has been recently crystallized bound into its receptor, a G-protein coupled receptor [97]. In the complex, the peptide is shown to adopt an extended conformation, with the Cterminus buried in the orthosteric site, whereas the N-terminus faces the surface, in agreement with previous solid state NMR spectroscopy studies [98]. In this case, the peptide adopts a structure similar to the one found by NMR in solution under the influence of structuring solvents [99]. The nonapeptide bradykinin bound to the B2 receptor is another example of a peptide bound to a GPCR whose structure was solved by solid state NMR spectroscopy [100]. In this case, the peptide exhibits a distinct double $S$ shape with a $\beta$-turn on its $\mathrm{C}$-terminus.

Unfortunately, detailed information of the bioactive conformation is not available most of the time. Instead, sketchy information of the bioactive conformation can be obtained from spectroscopic methods or computer simulations, basically a secondary structure motif on the peptide segment [101]. In this case, the strategy followed for peptidomimetic design consist of producing conformationally constrained analogs aimed at reinforcing any hypothesis about a specific secondary structure motif present in the bioactive conformation [102]. However, rigidified analogs may or may not exhibit any conformational feature of the bioactive conformation. In the case they do, they are expected to have an increased binding free energy to the target protein due to the bioactive conformation population enhancement and a concomitant reduction of the entropic loss penalty upon binding. To guide this process it is necessary the use of spectroscopy and/or computational studies that provide information about the secondary structure of the peptide. However, caution should be exercised since the conformation a peptide attains in solution is not necessarily related to the bioactive conformation.

Rigidification makes peptides less flexible and therefore more pre-organized, displaying a higher affinity compared to linear counterparts, due to the enhancement of specific secondary structure motifs 
and to the reduction of the entropy cost upon receptor binding. This in turn provides peptide analogs with increased potency; more resistant against proteolytic degradation; increased selectivity and enhanced bioavailability. A simple procedure to rigidify the structure of a peptide and simultaneously enhance specific secondary structure motifs is cyclization [103]. As an alternative to cyclization, rigidified analogs can also be produced by replacement of specific amino acids of the sequence for non-coded conformationally constrained amino acids [104].

\section{The Medicinal Chemistry Approach}

\section{Globally Constrained Analogs}

Cyclization increases peptide resistance to proteases degradation as well as cell permeability and leads to exceptional physicochemical stability, so that cyclic peptides constitute an important class of therapeutic peptides $[105,106]$. Cyclic peptides can be formed via backbone (head-to-tail cyclization); via linkage of side chain functionality to the $\mathrm{N}$-/C-terminus; or via the linkage of a side chain to another side chain [107]. In this latter case there is a diversity of structures possible, including macrocyclic disulfides formed by two cysteines, thioethers, lactams or lactones. Cyclization can also be formed through an ester bond giving rise to a series of compounds known as cyclic depsipeptides. Figure 4 displays different possibilities of peptide cyclization. Giving this versatility to produce cyclic peptides, cyclization can be used to produce a global conformational constraint on the peptide or just produce a local constraint when cyclization occurs in a short segment of the peptide.

Proof of the relevance of cyclic peptides as drug candidates comes from the fact that most of the peptides produced by diverse organisms for predation, defense or competitor deterrence are cyclic. Actually, these are compounds designed to produce a physiological response on a guest organism and consequently they require having improved pharmacokinetic properties. Cyclic peptides found in nature exhibit diverse pharmacological activities, including antibiotic, immunosuppressive, cytotoxic or neurotoxic. For example, a paradigmatic example of antibiotic peptide is the vancomycin [108]. It is a bicyclic peptide formed via side-chain/side-chain cyclization and represents an example of a comparatively rare haloorganic natural compound. Vancomycin is naturally produced by a species of the actinobacteria, a group of Gram-positive bacteria found in soil. Cyclosporin A is a paradigmatic example of immunosuppressive drug extensively used in organ transplantation to prevent rejection [109]. Cyclosporin A is a cyclic undecapeptide with the cycle closure formed by a lactam. The peptide has few non-proteinogenic residues, including a D-Ala in position 8 , although its most important differential feature is that seven out of the eleven residues are $\mathrm{N}$-methylated. Keramamide $\mathrm{F}$ is a cylic heptapeptide found in marine sponges of the genus Theonella with cytotoxic activity [110]. The peptide contains non-proteinogenic amino acids such as (O-methylseryl)thiazole, $\alpha, \beta$-dehydrotryptophan, isoserine, 2,3-diaminopropionic acid, and 3amino-4-methyl-2-oxohexanoic acid and cyclization occurs through the link of the side chain of the 2,3diaminopropionic acid to the $\mathrm{C}$-terminus through a lactam bond. Finally, there are cyclic peptides among the toxins produced by cyanobacteria, including the microcystins and nodularins [111]. These compounds 
are inhibitors of the protein phosphatase type 1 and type $2 \mathrm{~A}$, leading to an increase in phosphorylation of proteins in liver cells. Microcystins are cyclic heptapeptides that contain diverse non-proteinogenic amino acids, such as the $\beta$-amino acid (2S,3S,8S,9S,4E,6E)-3-amino-9-methoxy-2,6,8-trimethyl-10-phenyl-4,6decadienoic acid (ADDA), D-Ala and D-methylaspartate. Cyclization is produced through the side chains of the two D-methylaspartates. Eighty microcystins have been identified to date, representing differences in two variable residues and some modifications in the other amino acids. Microcystin-LR is the most extensively studied and is named because it contains Leu and Arg occupying the variable residues of the peptide.

A paradigmatic example of the development of synthetic cyclic peptides for therapeutic purposes comes from the design and synthesis of a series of RGD analogs targeting cell adhesion receptors. These cyclic analogs contain the fragment Arg-Gly-Asp (RGD) known to be a common element in cellular recognition and specifically, a binding epitope for membrane-bound integrins. Thus, by controlling the conformation of the ring and consequently that of the RGD motif, Kessler and collaborators $[112,113]$ were able to design and synthesize selective cyclic RGD peptides for the $\alpha$ llb $\beta 3$ and for the $\alpha v \beta 3$ integrins. The former with applications as antithrombotic agent, whereas the latter as anticancer drug through the prevention of angiogenesis and by inducing apoptosis in vascular cells.

Another interesting example of the use of a cyclic peptide designed to preserve the bioactive conformation of a larger peptide segment is exemplified in the story behind the discovery of somatostatin analogs. Based on the hypothesis that the tetrapeptide segment Phe Prp $^{8}-$ Lys $^{9}-$ Thr $^{10}$ in somatostatin is involved in a $\beta$-turn in its bioactive form and that much of the remainder of the hormone apparently functions as scaffold, researchers at Merck found a somatostatin analog 1.24 times more active than somatostatin in a cell culture assay [114]. Using the structure of this compound as reference and after a careful molecular modeling study, a series of smaller cyclic hexapeptides up to 1.7 times more potent that somatostatin were design and synthesized [115].

A more recent example is exemplified by the design of cyclic analogs of the $\alpha$-melanocytestimulating hormone $(\alpha-\mathrm{MSH})$ [116]. The hormone is a tridecapeptide of sequence Ac-Ser ${ }^{1}$-Tyr ${ }^{2}-$ Ser $^{3}$ -

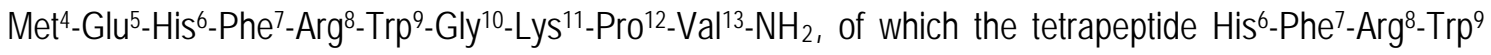
forms the essential active core. With this idea in mind, there were synthesized several cyclic analogs that provide the tetrapeptide diverse conformations. The first cyclic analogs designed involved the replacement of $\mathrm{Met}^{4}$ and Gly ${ }^{10}$ by cysteine residues to form a disulfide bond. The compound is a potent analog but lacked prolonged biological potency. This compound was later improved with the discovery of MT-II with sequence Ac-Nle-c[Asp-His-D-Phe-Arg-Trp-Lys]- $\mathrm{NH}_{2}$ (Nle = norleucine), a potent agonist with prolonged biological potency. Subsequent modifications of MT-II lead to design selective analogs to the diverse melanocortin receptors.

As mentioned above, cyclization can also promote local conformational changes on a peptide. As an example, aiming at stabilizing a helical conformation, side chain-side chain cyclization between $\mathrm{Glu}^{30}$ 
and Lys ${ }^{33}$ in corticoprin-releasing factor through a lactam ring, played an important role in the discovery of astressin a potent corticoliberin 2 (CHR2) antagonists [117].

\section{Local Rigidification Using Conformationally Constrained Residues}

A different approach to rigidify the structure of a peptide is the inclusion of conformationally constrained amino acids in the sequence. The inclusion of these amino acids aims to produce analogs with local conformational constraints which eventually exhibit improved affinities by diminishing the entropy cost occurred upon binding to their receptors. Constraints can be applied to the backbone or to the side chain dihedral angles [104]. The former induce a local modification on the structure of the peptide chain, whereas the latter are intended to block side chains in specific conformations. Proline is the only of the twenty natural amino acids with its backbone conformational space constrained due to the covalent bond between the side chain and the amine nitrogen. As a consequence the $\Phi$ angle is restricted to adopt values close to $-60^{\circ}$. The cyclic structure also confers a low cis-trans isomerization barrier to the peptide bond preceding a proline in a polypeptide chain $\left(20-22 \mathrm{kcal} \mathrm{mol}^{-1}\right)$ [118]. Actually, this process constitutes one of the most widespread molecular switches in biochemical pathways and it is known to be the ratedetermining step in the folding [119] and denaturing of proteins [120]. Its conformational rigidity affects the secondary structure of proteins and may account for its higher prevalence in the proteins of thermophilic organisms. Proline acts as a structural disruptor in the middle of regular secondary structure elements such as alpha helices and beta sheets; however, it is commonly found in turns and as the first residue of an alpha helix and also in the edge strands of beta sheets [121]. A different way to induce a local constrain in the peptide backbone is through a $\alpha$-substitution, in which the hydrogen of the $C^{\alpha}$ is substituted by an alkyl chain. One of the most important examples of this kind of residues is the $\alpha$-aminoisobutyric acid also referred as methylalanine (Aib) $\mathbf{3 4}$ (Figure 3) found in transmembrane channel-forming peptide antibiotics known generically as peptaibiotics (peptide antibiotics with high Aib content) [122]. Dehydroalanine 35 (Figure 3) also found in some natural non-ribosomally synthesized peptides represents a different way to constrain the backbone through a $C^{\alpha}-C^{\beta}$ double bond. On the other hand, side chains can be constrained in different ways. For example, adding a substituent in $C^{\beta}$ makes the amino acid to exhibit an important constraint in its conformational space. Natural amino acids like valine, isoleucine or threonine exhibit a $\beta$ substitution. Inspired by these constrained amino acids, a series of new amino acids with a limited availability of the conformational space have been designed in the last years.

$C^{\alpha, \alpha}$-dialkylated amino acids represent one of the most widely studied families of non-coded amino acids [123]. These amino acids confer severe restrictions to the polypeptide chain through an important reduction of the conformational space available, favoring specific secondary structures. The most extensively investigated member of the family is Aib. The presence of a second methyl group at the $C^{\alpha}$ restricts the backbone conformational space available to the helical region with a higher propensity to form $3_{10}$ rather than $\alpha$-helices [124]. Interestingly, the achiral nature of Aib permits the residue to participate in right- and left-handed helices with the same propensity. Accordingly, Aib plays an important role as helix 
enhancer when inserted in a polypeptide chain, as has been observed both, in solution as well as in crystal structures [125]. Other members of the series exhibit differential conformational profiles. Thus, the achiral $C^{\alpha, \alpha}$-symmetrically disubstituted glycines, like in $\alpha$-diethylglycine, $\alpha$-di-n-propylglycine or $\alpha$-di-nbutylglycine tend to adopt $\mathrm{C} 5$ conformations stabilized by an intramolecular hydrogen bond, inducing the peptide backbone to adopt an extended conformation [126]. On the other hand, the achiral analogs exhibit a different profile. Isovaline, also referred as ethylalanine (Iva), the simplest achiral member of the family is a strong helix enhancer. Like Aib it is capable to participate in both right- and left-handed helical structures. However, due to the chirality of the $C^{\alpha}$ the two isomers exhibit a differential conformational behavior, with the D-Iva exhibiting a higher tendency to form left-handed helical structures [127], whereas L-Iva tends to favor right-handed ones [128]. In regard to the $\alpha$-methyl derivatives of natural amino acids, they are strong inducers of $\beta$-turns or right-handed $3_{10}$-helical structures depending on the chain length. Interestingly, those amino acids that are $C^{\gamma}$-branched like $\alpha$-methylphenylalanine, $\alpha$-methylleucine or $\alpha$ trptophan tend to generate the opposite screw sense of helicity [122].

The two alkyl chains of $C^{\alpha, \alpha}$-dialkylated amino acids can be part of a ring. This gives rise to the 1amino-cycloalkane-1-carboxylic acids $\left(A c_{n} c\right) 36$ (Figure 3), where $n$ is the number of carbon atoms in the ring [129]. These amino acids induce almost exclusively helical conformations to the peptide chain [121]. The simplest one of the series is the 1-aminocyclopropanecarboxylic acid $\left(\mathrm{Ac}_{3} \mathrm{C}\right)$, naturally found in diverse compounds like in the nonadepsipeptide BZR-cotoxin II [129]. This depsipeptide is produced by fungus that causes leaf spot disease in corn. The insertion of $\mathrm{AC}_{3} \mathrm{C}$ in a polypeptde chain produces interesting conformational restrictions. Indeed, inspection of its Ramachandran map suggests that this amino acid adopts as preferred conformation when $\phi$ is around $\pm 80^{\circ}$ and $\psi$ is around $0^{\circ}$, what makes an interesting residue to be in position $i+2$ of both type I and type II $\beta$-turns. In addition, the residue can also accommodate distorted type III bends and $3_{10}$-helices [130].

These residues have successfully been used to reduce the conformational freedom of diverse peptide ligands. Thus for example, in the search for sweeter compounds than the dipeptide L-Asp-PheOMe (aspartame), diverse analogs were synthesized, being L-Asp-Ac 3 C-OMe 37 (Figure 5) a very active compound with a sweet taste of up to 300 times stronger than that of sucrose [131]. Another example is given by the analog L-Pro-L-Leu- $\mathrm{Ac}_{3} \mathrm{CNH}_{2} 38$ (Figure 5), where Ac3c substituted Gly, shows an increased binding affinity in regard to its parent compound to the dopamine D2 receptor, an effect which is postulated to be useful in the treatment of extrapyramidal motoric disorders such as Parkinson's disease and depression [132]. Another example is represented by the acetyl derivative of the $\mathrm{N}$-2(S)mercapto-3methyl-1-oxobutyl-AC5C-Tyr (CGS 30440) 39 (Figure 5), a dual inhibitor of the neutral endopeptidase and the angiotensin-I converting enzyme that is clinically applied in the treatment of hypertension and congestive heart failure [133]. 
Molecular diversity can be increased to the cyclic $C^{\alpha, \alpha}$-dialkylated amino acids by attaching substituents to the ring. Residues of this kind are found as natural products like (-)-coronamic acid $\mathbf{4 0}$ (Figure 5) found in the plant toxin coronatine [134]. These amino acids preserve the conformational features of the corresponding parent compounds constraining the backbone chain locally and exhibit functional side chains. Moreover, side chains are also constrained, exhibiting defined values of the $\chi^{1}$ side chain angle forcing specific orientations of the corresponding functional groups. These amino acids have however the drawback that substituents normally add chiral centers to the molecule and consequently, require stereoselective synthesis [135]. The most extensively studied amino acids of this kind of amino acids are the derivatives of the twenty occurring amino acids and specially the phenylalanine derivatives due to the involvement of aromatic rings in intermolecular interactions in peptides. Thus for example, the amino acid produced by the attachment of a phenyl group to the cyclopropane cycle in $\mathrm{Ac}_{3} \mathrm{C}$ : the 1aminophenylcyclopropane-1-carboxylic acid ( $\left.c_{3} P h e\right)$ is a constrained phenylalanine that exhibits the aromatic ring in very specific conformations. There are four stereoisomers possible $(2 \mathrm{R}, 3 \mathrm{~S})-\mathrm{C}_{3} \mathrm{Phe} 41$; $(2 \mathrm{R}, 3 \mathrm{R})-\mathrm{C}_{3}$ Phe $42 ;(2 \mathrm{~S}, 3 \mathrm{~S})-\mathrm{C}_{3}$ Phe 43 and $(2 \mathrm{~S}, 3 \mathrm{R})-\mathrm{C}_{3}$ Phe 44 (shown in Figure 5) that exhibit slightly different conformational propensities. This behavior can be seen in the four analogs of the peptide Ac-LPro- $C_{3}$ Phe-NHMe adopt $\beta$ I-type and $\beta$-II type turn conformations, however they exhibit a differential type I/type II proportion [136]. These amino acids have been used in many occasions to design more potent peptide analogs by restricting the conformational space available to conformations close to the bioactive form [137]. Thus for example, one of the stereoisomers of the analog Phe- $\mathrm{C}_{3} \mathrm{Met}-\mathrm{Arg}-\mathrm{PheNH}_{2}$ was shown to exhibit an improved anti-opiate activity in regard to the parent compound [138]. Amino acids with bulkier cycloalkane moieties have also be synthesized, like the adamantyl amino acid (2-aminoadamantane-2 carboxylic acid) 45 (Figure 5). This amino acid has interesting properties like being resistant to proteolytic degradation and an helper of blood-brain-barried crossing, due to the bulkiness and hydrophobicity of its side chain. From the structural point of view adamantanine is a $\gamma$-turn inducer [139]. Although its use in drug design is limited, there are interesting examples of its use. This, for example the adamantyl amino acid is present as moiety in meclinertant 46 (Figure 5), the first a non-peptide antagonist found at the neurotensin receptor-1. The compound crosses the blood-brain-barrier and it is currently used to explore the interaction between neurotensin and other neurotransmitters in brain [140].

It can also be considered cyclic $\mathrm{C}^{\alpha, \alpha}$-dialkylated amino acids that some of the atoms of the ring substituted by heteroatoms. These amino acids are interesting since in addition to constrain the peptide backbone, add certain functionality that can be useful in molecular recognition. Thus, for example a disulfur substituted $\mathrm{Ac}_{5} \mathrm{c}$ : the 4-amino-1,2-dithiolane-4-carboxylic acid $\mathbf{4 7}$ (Figure 5) is an excellent inhibitor of the synthesis of S-adenosyl-L-methionine a cofactor in various enzyme-catalyzed reactions of which transmethylation are the most significant [141].

Another important group of non-coded residues conformationally constrained residues are the $\alpha, \beta$ dehydroamino acids (represented as $\Delta \mathrm{Xaa}) 35$ (Figure 3) whose distinctive feature is to have a double 
bond between $C^{\alpha}$ and $C^{\beta}$ [142]. The simplest member of the family is the dehydroalanine $(\Delta \mathrm{Ala})$ that is found together with dehydrobutyrine ( $\triangle \mathrm{Abu})$ in a class of antibiotics known as lantibiotics, including members like nisin, epidermin, and subtilin [143]. These peptides are ribosomally synthesized and subjected to posttranslationally modifications involving a two-step procedure in which selected threonine and serine residues are enzymatically dehydrated to form $\Delta \mathrm{Abu}$ and $\Delta \mathrm{Ala}$ respectively, followed by a stereoselective intramolecular Michael-type addition of Cys thiols to the newly formed dehydroamino acids to form sulfur-to- $\beta$-carbon thioether cross-links [144].

In regard to their structure, $\alpha, \beta$-dehydroamino acids constrain the peptide backbone to adopt $\beta$ turns in short sequences and helices in longer ones, as well as restrict the side chain in the $\mathrm{E}$ or $\mathrm{Z}$ position. As in the case of other non-natural amino acids they exhibit an enhanced proteolytic stability and due to their distinctive features have been used for the design of synthetic analogues. An interesting application is exemplified by the recent report of a small peptide of sequence Phe-Gly-Ala- $\Delta$ Phe-Leu found to inhibit fibril formation of the human islet amyloid polypeptide, involved in the development of type 2 Diabetes Mellitus [145], although, most of the current application are in the field of de novo design of antibiotics [146].

An interesting group of amino acids that restrict the conformational freedom of a peptide chain are the 1-azacycloalkane-2-carboxylic acids, i.e. residues with a cyclic side chain and with the amino group forming part of the ring. This family of compounds is inspired by proline, the 2-is the pyrrolidinecarboxylic acid 48 (Figure 6) that is the five-member ring of the series. Other members of this series include the 2aziridinecarboxylic acid 49 (Figure 6), the analog with a three member ring; the 2-azetidinecarboxylic acid 50 (Figure 6), the analog with a four member ring; or the 2-piperidinecarboxylic acid 51 (Figure 6) the analog with a six member cycle. It can also be thought of derivatives of $\beta$-proline [147]. For example, the analog of endomorphin-2 (Tyr-Pro-Phe-Phe-NH 2 ) with the phenyl $\beta$-proline derivative 4-phenylpyrrolidine3-carboxilic acid $\mathbf{5 2}$ (Figure 6) replacing proline is a potent opioid derivative with dual antinociceptive and antidepressant actions [148]. Moreover, rings can have substituents attached as well as heteroatoms. Indeed, there are several analogs of proline found in natural compounds as the result of posttranslational modifications of the residue. For example, the cis-4-methyl-L-proline was found in the hydrolysis of leucinostatine or the trans-4-hydroxy-L-proline was first found in hydrolysates of a sponge [146]. Synthetic proline analogs have been used for drug design like for example, the dimethyl derivative of the thioproline, the 5,5-dimethylthiazolidine-4-carboxylic acid $\mathbf{5 3}$ (Figure 6) is an amino acid that forms part of a potent inhibitor against plasmepsins, a group of aspartic proteases found in the lethal malarial parasite $P$. falciparum that are vital for its survival [149].

Proline derivatives may also have a fused ring giving rise to bicyclic amino acids. Examples are the 2-indolinecarboxylic acid $\mathbf{5 4}$ (Figure 6) or the tetrahydroisoquinoline-3-carboxylic acid (Tic) $\mathbf{5 5}$ (Figure 6). These amino acids have a restricted conformational space available: on the one hand, the backbone as in proline and on the other, the side chain dihedral $\chi^{1}$. For example, Tic has $\chi^{1}$ constrained to take only the 
values $+60^{\circ}$ or $-60^{\circ}$. Accordingly, these compounds should be considered as constrained phenylalanines. One successful example of the use of Tic for drug design is exemplified in the search for new angiotensin converting enzyme inhibitors. Replacement of proline with Tic in enapril 56 (Figure 6), led to quinapril 57 (Figure 6) approved by the FDA in 1991 [150].

Side chains can also be constrained via the introduction of substituents at the $\beta$-carbon and it is a simple strategy to synthesize constrained amino acids. These modifications do not perturb the backbone conformation much and still allow side chains certain flexibility. Actually, three of the twenty natural occurring amino acids including valine, isoleucine and threonine show $\beta$-disubstitutions. Other $\beta$ substituted amino acids are also found in nature. For example, $\beta$-dimethylcysteine (penicillamine) $\mathbf{5 8}$ (Figure 6) is a metabolite of penicillin. This amino acid has been used in the past to generate constrained peptides. Specifically, it was used to design the cyclic analog (D-Pen²,D-Pen ${ }^{5}$ )-enkephalin (DPDPE), one of the most selective and potent opioid peptides interacting with the $\delta$-receptor [151]. In regard to newly synthesized amino acids, both $\beta$-methyl and $\beta$-phenyl-substituted analogs of aromatic amino acids are the most extensively studied [152]. The effects of $\beta$-substitution on the biological properties of a peptide depend on the chirality of the stereoisomers. They have been useful in improving our knowledge of the features of the binding site of diverse receptors or discover more potent analogs. Thus, for example the features of the different $\beta$-methylphenylalanine 59 (Figure 6) isomers were used to ascertain the pharmacophoric features of the $\delta$-opioid receptor [153]. Another interesting example is the use of $\beta$ diphenylalanine 60 (Figure 6) for the discovery of a potent antibiotic enhancer [154].

\section{Local Rigidification Using Dipeptide Mimetics}

As mentioned above, the ability of a peptide to adopt a turn at a specific position of the chain can be crucial to adopt its bioactive conformation necessary to interact with a specific receptor. This is particularly important in the case of peptide ligands of G-protein coupled receptors [155]. Dipeptide mimetics can be used to design molecules that mimic the conformational role of specific residues of the chain by introducing local restrictions on the peptide backbone. Once it is established through structureactivity studies that a turn enhances peptide affinity, a step forward to design a peptidomimetic is to replace the residues involved in the turn by an organic scaffold. These dipeptide mimetics are designed with two reactive handles conveniently oriented in such a way that can be used to attach $\mathrm{N}$ - and $\mathrm{C}$ terminal polypeptide chains, in addition to preserve the necessary side chains for an adequate interaction with the receptor.

Cyclic lactams, known as Freidinger lactams after their discoverer, were one of the first dipeptide mimetics designed to mimic two consecutive residues involved in a $\beta$-turn [156]. Since then, cyclic lactams have been used thoroughly in the design of peptidomimetics [157]. This type of structures are found in natural products like penicillin G 61 (Figure 7), a potent antibiotic extracted from a fungus; dolastatin 1362 (Figure 7) a cytostatic depsipeptide isolated from a sea hare; or bengamides 63 (Figure 7), potent immune 
modulating agents extracted from a bacterium and from a sponge, respectively. The idea to utilize dipeptide lactams as conformational constraints in peptides was originated in a study involving a series of C3 symmetric cyclic hexapeptides, exemplified by the analog (Ala-Sar) ${ }_{3}$ [158]. These peptides have cation binding properties and had been studied for their capacity to improve feed efficiency in ruminant animals by shifting ruminant stomach bacterial fermentation toward the production of less volatile products. A molecular modeling study of these cyclic peptides suggested that building a bridge from the $C^{\alpha}$ of alanine to the nitrogen of the succeeding sarcosine could be an effective way to constrain the ring 64 (Figure 7). The lactam ring can vary in size, ranging from a $\beta$-lactam resulting in a azetidinone ring; a $\gamma$-lactam for a five member ring resulting in a pyrrolidinone scaffold that can be considered to mimic a Gly-Ala dipeptide; a $\delta$-lactam with a six member ring resulting in a piperidone scaffold that mimics a Ala-Ala dipeptide; a $\varepsilon$ lactam with a seven member ring resulting in a azepanone scaffold or even larger as for example the azoninone ring proposed to design type II' $\beta$-turns [159]. These series of substituted lactams offer a diversity of structures to mimic constrained dipeptides and can be expanded further by incorporating heteroatoms to the ring [160].

Other heterocycles have also been used as scaffold for peptidomiemtic design [161]. Thus, in the case of the piperidone ring -the six member cyclic lactam- diverse modifications have been considered like the addition of a second nitrogen to the cycle, giving rise to the piperazinone ring 65 (Figure 7). This scaffold has been used in the past to design diverse constrained analogs such as peptidomimetics of the sequence CAAX, where $X$ is usually leucine or phenylalanine, as potent inhibitors of the enzyme geranylgeranyltransferase for the treatment of cancer [162]. Adding a second ketone group to the piperidone ring generates the diketopiperidine scaffold 66 (Figure 7), a surrogate of the Ala-Gly dipeptide [163]; or to the piperazinone ring generates the diketopiperazine scaffold 67 (Figure 7) [164]. This latter, in addition to appear in diverse natural products like trypostatins, brevianamides, rosstratins $A$ or vertihemiptellides [165], has been extensively used for new drug discovery. Examples include its use for the development of oxytocin antagonists [166] or as tubulin polymerizing agent with antitumor activity [167].

In regard to seven-member rings there are also diverse scaffolds based on the corresponding cyclic lactone: azepanone. Thus, the incorporation of extra nitrogens to the ring generates diazepanones like 68 (Figure 7) [168] or cyclic ureas like 69 (Figure 7) [169] and triazepanones 70 (Figure 7) [170] that have been used as scaffold in peptidomimetic design with the purpose to mimic $\gamma$-turns. However, the most extensively seven member rings used are the diazepinones 71 (Figure 7) that exhibit the ring partially unsaturated.

Freidinger lactams as well as other heterocycles can also be part of a bicyclic scaffold, opening the door to the design of a vast diversity of compounds $[171,172]$. Ring annelation can be done through the addition of an aromatic ring to the cyclic lactam. These bicycles can be considered mimetics of the phenylalanylglycine dipeptide that hold the phenyl side chain oriented in the "anti" conformation $\left(\chi^{1}=\right.$ 
$180^{\circ}$ ). For example, the benzoazepinone scaffold 72 (Figure 7) has been used for the design of potent and specific farnesyl transferase inhibitors [173]. An aromatic ring fused to a diazepinone generates the benzodiazepinone scaffold 73 (Figure 7), extensively used in peptidomimetic design. Thus for example, a benzothiazepine bicycle $\mathbf{7 4}$ (Figure 7) has been used for the development of potent angiotensin converting enzyme inhibitors [174]. Actually, this scaffold is well known in pharmacology since diverse analogs based on this scaffold belong to an exclusive class of drugs with anxiolytic profile that act as positive allosteric modulators of the inhibitory neurotransmitter GABA binding to the so-called benzodiazepine receptor [175].

Cyclic lactams can also be set up using the skeleton of a proline residue giving rise to azabicycloalkane scaffolds 75 (Figure 7). Compounds with a six or seven member ring annealed to a proline skeleton have been used to rigidify the structure of peptide analogs, like the RGD analogs recently disclosed as potent integrin antagonists [176] or a set of analogs designed as thrombin inhibitors [177]. These bicyclic scaffolds can also be used to produce rings of diverse size, including diverse substituents and/or heteroatoms in the rings [172], or design from them more complicated structures. Thus for example, compound $\mathbf{7 6}$ (Figure 7) contains a benzoazabicycloalkane scaffold that mimics the dipeptide Phe-Leu, exhibiting a pharmacological profile as potent dual inhibitor of angiotensin converting enzyme and neutral endopeptidase 24.11 [178]. An alternative to these structures consists of the attachment of an additional ring to produce a spiroazabicycloalkane scaffold 77 (Figure 7). This scaffold has been used successfully in peptidomimetics of the Pro-Leu-GlyNH $\mathrm{N}_{2}$ tripeptide as allosteric modulators of the dopamine D2 receptor [179]. It can be thought also in using a tricycle scaffold by closing a ring structure between two consecutive prolines. In this direction, the derived diketopiperazine template has successfully been used to design molecules that works as model receptors of tripeptides and that could be used pharmacologically as a non-competitive antagonist [180].

Other organic scaffolds designed to generate turns in a peptide chain have been used in the past. These scaffolds are inspired by the D-Pro-L-Pro dipeptide 78 (Figure 8), known to adopt a stable type II'- $\beta$ turn [181] and designed to provide two reactive handles which can be used to attach $\mathrm{N}$ - and $\mathrm{C}$ - terminal polypeptide chains. Among them, the diketopiperazine incorporating a substituted proline 79 (Figure 8) has demonstrated to be a useful scaffold [182]. On the other hand, diverse biaryl scaffolds have been described in the literature including biphenyl 80 (Figure 8) [183]; diphenyltriazole 81 (Figure 8) [184]; dibenzofuran 82 (Figure 8) [185]; diphenylacetylene 83 (Figure 8) [186]; xanthene scaffolds 84 (Figure 8) [187]. Similarly, the condensed bicycles like naphthalene 85 (Figure 8) and quinoline 86 (Figure 8) have also been utilized in the design of HIV protease inhibitors [188]. Other strategy to design turn mimetics has been to attach two aromatic rings to a scaffolding molecule like urea. Thus, the dimethyldiphenylurea 87 (Figure 8) has been used as template to design somatostatin analogs [189]. In the same direction, diurea scaffolds have been used to hold two $\beta$-strands forming a parallel $\beta$-sheet 88 (Figure 8) [190]. More recently an azobenzene scaffold 89 (Figure 8) has been used as template to synthesize cyclic somatostatin analogs [191]. This scaffold has the feature to change conformation upon light absorption. 
So that, when it is in the cis conformation helps to the rest of the peptide chain to form a $\beta$-turn, whereas in the trans conformation the peptide segment does not acquire its bioactive conformation. Accordingly, this scaffold allows modulating the three-dimensional structure and biological activity upon light exposure.

\section{Designing Peptides and Peptidomimetics with Preferred Conformations other than Turns}

Natural amino acids exhibit differential preferences to adopt specific secondary structures due to the nature of their side chains. Obviously, this can also be extended to non-proteogenic amino acids widening the repertoire of possibilities to design peptide analogs with specific conformational preferences. Accordingly, a careful selection of a sequence together with a wise incorporation of unnatural amino acids in the polypeptide chain can help to enhance a specific secondary structure in an analog. In this direction, a great deal of interest has been devoted in the last years to develop procedures to synthesize analogs mimicking a-helices, $\beta$-sheets or hairpin turns [192]. The interest of designing sequences with a specific secondary structure is of great interest in drug design particularly, in protein-protein interactions. These molecules are aimed at mimicking protein epitopes with increased binding affinity of protein, avoid rapid degradation and eventually, to increase membrane permeability. Moreover, the interest of designing these molecules goes beyond the biomedical arena, being of great interest in the field of constructing artificial receptors or in a broader sense in nanotechnology, as a tool to construct structures for specific purposes [193].

Helices are important structural elements in biomolecular recognition and have been focus of attention for many years. The main focus of interest in regard to drug design has pivoted around three different topics: helicity enhancement of natural ligands known to adopt helical structures; helicity enhancement of specific antimicrobial peptides, since this has been found to be a determining factor for antibiotic activity; and, the design of helical peptides or mimics acting as inhibitors of protein-protein interactions. Accordingly, there is an ample literature describing the design of helical peptides and peptidomimetics [194].

In order to design helical peptides it should be taken into account that not all the 20 proteogenic amino acids exhibit the same propensity to adopt $\alpha$-helices. Thus, it is known that Leu, Glu or Lys, as well as short stretches of alanine are strong stabilizers of this secondary structure [195]. In addition to make use of the tendency of natural residues to adopt a helical structure, several strategies have been used in the past to enhance peptide helicity [196]. The simplest procedure is to incorporate helicogenic residues to the sequence. Thus, $C^{\alpha, \alpha}$-dialkylated amino acids [197] as well as $\beta$-amino acids have been widely used for this purpose [198]. For example, a series of $\beta$-peptides have successfully been designed to mimic the helical peptide MDM2, a natural negative regulator of the tumor suppressor p53 for the treatment of breast cancer [199].

When designing a peptide aimed at adopting a helical structure, careful attention needs to be given also to the edges of the helix. In fact, the N-terminus of a $\alpha$-helix has four amide hydrogens lacking the 
characteristic backbone hydrogen bond interactions and the C-terminus also has four free carbonyl groups. So, it is recommended to use appropriate residues before and after the helical segment (capping residues) in order to avoid unfavorable charge interactions with the helix dipole and with specific side chains and, to provide the possibility to form hydrogen bonds to those residues at the beginning or end of the helix in order to stabilize it. Amino acids like Asn, Asp, Ser, Thr, and Cys that can accept hydrogen bonds from otherwise free backbone NH groups exhibit the highest N-cap preference [200]. On the other hand, there is little variation in C-cap preference of the different amino acids apart from the widespread occurrence of Gly at this position due to its capability to adopt a left-handed conformation without an energy penalty [201]. In addition to the importance of capping residues for helix formation, there have been identified a few local motifs that stabilize the edges of the helix. At the N-terminus two motifs have been identified. The first, called capping box that involves a hydrogen bond the peptide bond amide and the side-chain of a Glu or Asp residues at position N3. The second, called hydrophobic staple, is the result of a hydrophobic interaction between the side-chains of two residues located at positions N' (residue previous to the N-cap) and N4, plus a good capping residue. Moreover, the presence in phase of a hydrophobic staple and a capping box motif stabilizes strongly the helical conformation [202]. At the $C$ terminus there is a motif identified for helix termination by Gly, called the Schellman motif, that consist of a Gly at position i; a hydrophobic residue at positions $\mathrm{i}-4$ and $\mathrm{i}+1$; and a polar or Ala residue at position i 2 [203]. However, although this motif is found in proteins it does not help helix formation of short peptides in solution [204]. Another local C-terminal motif found in $\alpha$-helices the so-called Pro-capping motif, consisting in X-Pro pairs (with X= Asn, Cys, His, Phe, Tyr, Trp, Ile, Val and Leu), in which residue $X$ is the C-cap and the Pro is a residue after [205].

A step further to enhance peptide helicity consists of cross-linking side chains of residues distant one helix turn. Thus the hydrogen bonding, charge-charge interaction or hydrophobic/aromatic interactions between residues lying on the same face of the helix has shown to be a good strategy. Moreover, this effect can be further reinforced through a chemical link using lactams, disulfides or metal ion coordination complexes among a variety of other linkages [206]. Thus for example, the use of side chain lactams in its $\mathrm{N}$-terminus was pivotal in confirming the helical nature of the bioactive conformation of the Human Parathyroid Hormone [207]. Stabilization of $\alpha$-helices can also be done through hydrocarbon cross links. The approach consists of incorporating covalent bonds of the type $C=X-Y-N$ as surrogates of the helical $i$, i+4 hydrogen bonds. Specifically, the process requires the incorporation of amino acids with olefinic side chains in order to enable an intramolecular metathesis reaction to get a "stapled" helix [208, 209]. This approach produces peptides that in addition to have higher affinities than their templates, exhibit increased proteolytic instability and enhanced membrane permeability. This technique has been used to design diverse bioactive peptides concerning the treatment of cancer including inhibitors of $\mathrm{Bcl}-2$ [210]; inhibitors of the tumor suppressor p53 [211]; the Notch transcription factor [212]; or the estrogen receptor [213]. The procedure has been shown successful even for long helical peptide stretches. Thus for example a double-hydrocarbon stapled analog of the 36-amino acid peptide antiviral enfuvirtide described above, 
exhibits a fourfold increased potency in comparison to its template and exhibits an improved pharmacokinetic profile, including oral absorption [214].

Next step to mimic a helical ligand consists of using organic scaffolds capable to project key functional groups into the right directions. These mimetics can be classified into a wide group of molecules called scaffold mimetics that will be discussed in the following section [215].

$\beta$-strands are major secondary motifs that peptides adopt when bound to their receptors [85]. This structure is universally found in protease inhibitors [216] or in the of antigen to the major histocompatibility complex presentation process and it is also relevant to mimic some protein-protein interactions like those that occur in the so-called amyloid diseases, where $\beta$-strands could be useful is to interfere with peptide/protein $\beta$-strand aggregation [217]. Relatively few methods have been reported for fixing $\beta$-strand conformations to produce more potent ligands. Cyclization is a strategy to enhance this structure, either constraining the peptide in a macrocycle or to use side chain-side chain cyclization. Other strategies involve the replacement of a central peptide bond by an isostere that is flanked by peptidic or nonpeptidic appendages; or even replacement of the peptide backbone by an organic scaffold in such a way that relevant side chains can be directed properly, as will be discussed in the following section [218].

Diverse macrocycles constructed by condensing peptide side chains to the main chain have been shown to produce highly constrained tri- and tetrapeptide sequences in an extended conformation [219]. A common cyclization scheme involves an ether link and a para substituted aromatic ring to form a 15-17 member ring, like in compound 90 (Figure 9), a potent HIV protease inhibitor [220]. A more rigid cyclization scheme involves the use of a biphenyl ether scaffold to produce compounds like the angiotensin converting enzyme inhibitor K-13 (91 in Figure 9) [221] or the aminopeptidase B inhibitor OF4949-IV (92 in Figure 9) [222].

In regard to non-cyclic $\beta$-strand mimics, there are many examples produced using isostere dipeptides that are flanked by peptidic or nonpeptidic appendages. Apart of those isosteres described previously, a 5-amino-2-methoxybenzoic acid combined with a 1,2-diaminoethane diurea molecular scaffold (93 in Figure 10) [223]; the 1,6-dihydro-3(2H)-pyridinone (94 in Figure 10) [224] or the 4,5dihydro-2(3H)-pyrazinone (95 in Figure 10) [225] have successfully been used for designing $\beta$-strands mimics.

$\beta$-sheet is a major secondary structure motif found in proteins. It involves two $\beta$-strands interacting through a network of hydrogen bonds and hydrophobic interactions. When the $\beta$-strands run in the same direction the sheet is called parallel and anti-parallel when the two strands run in opposite directions. Analysis of the protein data base reveals that more than two thirds of two-stranded $\beta$-sheets are local in nature, forming $\beta$-hairpin turns [226]. It is considered that $\beta$-sheets play a major scaffolding role in protein architecture, and specifically $\beta$-hairpin turns are used as recognition epitopes for molecular recognition like in the hypervariable regions of antibodies or in some protein-protein and protein-DNA interactions [227]. 
$\beta$-hairpin formation depends on some combination of turn formation and cross-strand stabilization. Analysis of hairpin turns in the protein data bank reveals that the majority of loops found in proteins have five residues at the most. In the two-residue loops is most frequent to find reverse turns; in the threeresidue loops, residues 1 and 2 are often found adopting a type I $\beta$-turn and residue 3 is in the left-handed alpha-helical region; the four-residue loops often contain overlapping type I $\beta$-turn $/ 3_{10}$ helical segment. Loops with four and five residues with a proline residue exhibit a great propensity to adopt a cis peptide bond Xaa-Pro. In regard to the two strands it is important for peptidomimetic design to note that paired residues on opposite strands can exist at hydrogen-bonding and non-hydrogen bonding positions, being their side chains pointing to different sides of the hairpin, respectively.

It is well established that both the turn sequence as the $\beta$-strands are important for the formation of a stable $\beta$-hairpin. So that the use of consensus $\beta$-turn sequences and $\beta$-turn mimetics which promote chain reversal and intramolecular hydrogen bonding does not guarantee to nucleate $\beta$-hairpin formation in sequences that are known to adopt this structure in proteins [228]. The reason of this is that both local conformational propensities and long-range interactions are required for $\beta$-sheet nucleation and that longrange residue-residue side chain interactions appear to be much more important in $\beta$-sheet folding than in a-helix formation $[229,230]$. Accordingly, the intrinsic $\beta$-sheet propensities of the amino acids in the strands are as important as the establishment of sidechain-sidechain interactions across the strands. Thus, the design of $\beta$-hairpins needs to be tackled using $\beta$-sheet amino acid formers such as valine, isoleucine and threonine or and, aromatic residues such as phenylalanine, tyrosine or tryptophan and using stable $\beta$-turns, whose conformation serves to form the first hydrogen bond of the $\beta$-hairpin and helps stitch together subsequent residues that register in hydrogen-bonding positions. These considerations permitted to design the first stable $\beta$-hairpins [231].

Despite disulfide bonds between cysteine residues of adjacent strands in parallel $\beta$-sheets are rare among proteins, inter-strand disulfide bonds stabilize parallel $\beta$-sheets formed by an autonomously folding peptide in aqueous solution [232]. This strategy has been successfully used to design constrained peptide analogs like CVX15 a disulfide bond cross-linked $\beta$-hairpin peptide antagonist of the chemokine CXCR4 receptor [233].

A straightforward approach to design peptidomimetics of $\beta$-hairpin turns is using cyclic peptides [234]. These molecules are built by transplantation of the hairpin loop from a protein and stabilized using a constraining template like those described above. Interestingly, a convenient template used for macrocyclic $\beta$-hairpin mimetic design is the dipeptide D-Pro-L-Pro (78 in Figure 8), which itself is known to adopt a stable type II' $\beta$-turn [181]. When incorporated into cyclic peptide the template nucleates $\beta$-hairpin conformations possessing the preferred right-handed twist typically observed between adjacent antiparallel $\beta$-strands in proteins. 
Diverse $\beta$-turn mimetics have been used as constraining scaffolds in $\beta$-hairpin turn peptidomimetics [235] including dibenzofurans (80 in Figure 8) [185]; substituted diphenylacetylene (81 in Figure 8) [186]; diureas (86 in Figure 8) [189] or diketopiperazines incorporating substituted proline derivatives (79 in Figure 8) [182] using or not $\beta$-strand enhancers.

\section{The Biophysical Approach \\ Scaffold Peptidomimetics}

As shown in Figure 1 a different approach to design peptidomimetics involves the use of scaffolds that hold the chemical moieties involved in ligand-receptor recognition (pharmacophoric groups), in the appropriate directions. Obviously, this approach implicitly assumes that only the side chains form part of the key interactions with the receptor. As we have shown above, this procedure has proven to be successful for designing peptidomimetics based on peptides that adopt different types of secondary structures [28].

The idea of using an organic scaffold for peptidomimetic design was anticipated in the early 1980 [236] and, the proof of concept was not reported until a few years later with the design of an enkephalin analog (96 Figure 10) [237]. Subsequently, $\beta$-D-glucose was successfully used to design peptidomimetics of somatostatin with agonistic profile like compound 97 (Figure 10) [238]. A process for the identification of suitable scaffolds was reported a few years later. In that study the spatial requirements of the side chains of $\beta$-turns were analyzed, providing criteria to select $\beta$-turn mimetic scaffolds [239]. This approach was further revised and extended to identify scaffolds suited for the synthesis of chemical libraries [240]. This method has been used to search for suitable scaffolds, among them the trans-pyrrolidine-3,4dicarboximide 98 (in Figure 10) [241]; oxopiperazines 99 (in Figure 10) [242] or spiroquinolines 100 (in Figure 10) [243].

The concept of scaffold mimetics has also been used to design a-helix mimetics [212]. Specifically, the rationale of these peptidomimetics consists of finding a scaffold that can easily hold the functional groups of residues in positions $\mathrm{i}, \mathrm{i}+3 / i+4$ and $\mathrm{i}+7$. Several of such scaffolds have been described in the past including the terphenyl 101 (Figure 10) [244, 245]; terephtalamide 102 (Figure 10) [246]; biphenyl 4,4'-dicarboxamide scaffolds 103 (Figure 10) [247] among others. There have also been described scaffolds capable to be used for the synthesis of combinatorial libraries. In this direction, the oligoamide derivatives [248] are very attractive scaffolds due to their synthetic accessibility via amide bond formation and predictable conformational profile. These scaffolds have been used successfully for the design of helical peptidomimetics. a-helix mimetics have also been designed using an organic scaffold that points the side chains in the right directions.

Scaffold mimetics can also be used to mimic $\beta$-strands. They can be constructed using aromatic rings as spacers such as benzene; 1,5- or 1,6-naphtalene or biphenyl scaffolds. For example, in the quest for Ras farnesyltransferase inhibitors, several peptidomimetics of the peptide sequence Cys-Aaa-Aaa-X 
(where Aaa represents an aliphatic amino acid and X=Met or Ser) in an extended conformation where designed using this strategy. Specifically, the potent farnesyltransferase inhibitors 104 (Figure 11) [249] and 105 (Figure 11) [250] contain a para-disubstituted phenyl group and a naphtyl group, respectively. The use of aromatic spacers for $\beta$-strand design has led to mimetics composed of alternating aryl and other functional groups like the imidazolidin-2-one rings, in such a way that are adapted to display diverse side-chains 106 (Figure 11 ) [251]. Much larger $\beta$-strand mimics have also been described in pioneering reports, such as the 2,8-diaminoepindolidione 107 (Figure 11) [252] or the polypyrrolinones 108 (Figure 11) [253].

$\beta$-sheets constructs beyond $\beta$-hairpins are scarce. In fact, in some cases $\beta$-strand mimics are able to dimerize forming $\beta$-sheets. Specifically, the $\beta$-strand tripeptides mimic Hao 109 (Figure 11), comprising hydrazine, 5-amino-2-methoxybenzoic acid and oxalic acid groups dimerizes to form $\beta$-sheet constructs in noncompetitive organic solvents [254]. Linking Hao to the $\delta$-amino group of the ornithine side chain through an amide bond produces the Orn(i-PrCO-Hao) scaffold 110 (Figure 11) that can be used to generate $\beta$-sheet constructs [255]. Using a different strategy, the tetrasubstituted diphenylacetylenes 111 (Figure 11) [256] have successfully been used as direct linking spacer between two $\beta$-strands, permitting construct $\beta$-sheets avoiding the construction of a $\beta$-hairpin structure.

\section{Conclusions}

The present report aims to review different approaches described in the past to succeed in the process of designing peptidomimetics. Basically, there are two different approaches: a medicinal chemistry approach, where parts of the peptide are successively replaced by non-peptide moieties until getting a non-peptide molecule and a biophysical approach, where a hypothesis of the bioactive form of the peptide is sketched and peptidomimetics are designed based on hanging the appropriate chemical moieties on diverse scaffolds. The first is more traditional and has provided numerous peptidomimetics already in the market. From enzyme inhibitors like enapril and the recently developed HIV protease inhibitors among others to peptidomimetics of secretory peptides like losartan or icatibant among others. The second, it is getting momentum lately thanks to the quest for protein-protein interaction inhibitors, most of them mimics of protein epitopes. As an example, the recently approved venetoclax, a small molecule peptidomimetic of the Bak-BH3 peptide that enhances apoptosis through the inhibition of the Bcl$\mathrm{xL}$ protein for the treatment of chronic lymphocytic leukemia.

\section{Acknowledgements}

The author wants to express his gratitude to the multitude of collaborators present and in the past for helpful discussions. Special thanks are given to Prof. Ernest Giralt and to the late Dr. Gilda H. Loew for their insightful discussions on peptides and peptidomimetics. 


\section{References}

1. Humphrey, M. J.; Ringrose, P. S. Peptides and Related Drugs: A Review of Their Absorption, Metabolism, and Excretion. Drug Metabol. Rev. 1986, 17, 283-310.

2. Vlieghe, P.; Lisowski, V.; Martinez, J. and Khrestchatisky, M. Synthetic Therapeutic Peptides: Science and Market. Drug Discov. Today 2010, 15, 40-56.

3. Bork, K.; Yasothan,U.; Kirkpatrick, P. Icatibant. Nat Rev Drug Discov 2008, 7, 801-802.

4. Case, D.B.; Wallace, J.M.; Keim, H.J.; Sealey, J.E.; Laragh, J.H. Usefulness and Limitations of Saralasin a Partial Competitive Agonist of Angiotensin II. Am J Med 1976, 60, 825-836

5. Ondetti, M.A.; Rubin, B.; Cushman, D.W. Design of Specific Inhibitors of Angiotensin-Converting Enzyme: New Class of Orally Active Antihypertensive Agents. Science 1977, 196, 441-444.

6. Thiagarajan, P.; Wu, K.K. Mechanisms of Antithrombotic Drugs. Adv. Pharmacol. 1999, 46, 297-324.

7. Erdmann, F.; Weiwad, M. Calcineurin Inhibitors: Status Quo and Perspectives. BioMol Concepts, $2011,2,65-78$.

8. Kilby, J. M.; Hopkins, S.; Venetta, T. M.; DiMassimo, B.; Cloud, G. A.; Lee, J. Y.; Alldredge, L.; Hunter, E.; Lambert, D.; Bolognesi, D.; Matthews, T.; Johnson, M. R.; Nowak, M. A.; Shaw, G. M.; Saag, M. S. Potent Suppression of HIV-1 Replication in Humans by T-20, A Peptide Inhibitor of Gp41-Mediated Virus Entry. Nat. Med. 1998, 4, 1302-1307.

9. Dal Corso, A.; Pignataro, L.; Belvisi, L.; Gennari, C. avß3 Integrin-Targeted Peptide/PeptidomimeticDrug Conjugates: In-Depth Analysis of the Linker Technology. Curr.Topics Med. Chem., 2016, 16, 314329.

10. Sattler, M.; Liang, H.; Nettesheim, D.; Meadows, R.P.; Harlan, J.E.; Eberstadt, M.; Yoon, H.S.; Shuker, S.B.; Chang, B.S.; Minn, A.J.; Thompson, C.B.; Fesik, S.W. Structure of Bcl-XL-Bak Peptide Complex: Recognition Between Regulators of Apoptosis. Science 1997, 275, 983-986.

11. Fletcher, M.D.; Campbell, M.M. Partially Modified Retro-Inverso Peptides: Development, Synthesis, and Conformational Behavior. Chem. Rev., 1998, 98, 763-795.

12. Zuckermann, R. N.; Kerr, J. M.; Kent, S. B. H.; Moos, W. H. Efficient Method for the Preparation of Peptoids [Oligo(N-substituted glycines)] by Submonomer Solid-Phase Synthesis. J. Am. Chem. Soc. 1992, 114, 10646-10647.

13. Hill, T. A.; Shepherd, N. E.; Diness, F. and Fairlie, D. P. Constraining Cyclic Peptides To Mimic Protein Structure Motifs. Angew. Chem. Int. Ed. 2014, 53, 13020 - 13041.

14. Antosova, Z.; Mackova, M.; Kral, V.; Macek, T. Therapeutic Application of Peptides and Proteins: Parenteral Forever? Trends Biotech. 2009, 27, 628-635

15. Craik, D. J.; Fairlie, D. P.; Liras, S. and Price, D. The Future of Peptide-based Drugs. Chem. Biol. Drug Des. 2013, 81, 136-147.

16. Hirshmann, R. Medicinal Chemistry in the Golden Age of Biology: Lessons from Steroid and Peptide Research. Angew. Chem. Int. Ed. Eng. 1991, 30, 1278-1301.

17. Giannis, A.; Kolter, T. Peptidomimetics for Receptor Ligands-Discovery, Development, and Medical Perspectives. Angew. Chem. Int. Ed. Eng. 1993, 32, 1244-1267. 
18. Marshall, G. R. A Hierarchical Approach to Peptidomimetic Design. Tetrahedron 1993, 49, 3547-3558.

19. Gante, J. Peptidomimetics-Tailored Enzyme Inhibitors. Angew. Chem. Int. Ed. Eng. 1994, 33, 16991720.

20. Giannis, A.; Rubsam, F. Peptidomimetics in Drug Design. Adv. Drug. Res. 1997, 29, 1-78.

21. Perez, J.J.; Corcho, F.; Llorens, O. Molecular Modeling in the Design of Peptidomimetics and Peptide Surrogates. Curr. Med. Chem. 2002, 9, 2209-2229.

22. Bursavich, M. G.; Rich, D. H. Designing Non-Peptide Peptidomimetics in the 21st Century: Inhibitors Targeting Conformational Ensembles. J. Med. Chem., 2002, 45, 541-556.

23. Vagner, J.; Qu, H.; Hruby, V. J. Peptidomimetics, a Synthetic Tool of Drug Discovery. Curr Opin Chem Biol. 2008, 12, 292-296.

24. Grauer, A.; König, B. Peptidomimetics - A Versatile Route to Biologically Active Compounds. Eur. J. Org. Chem. 2009, 5099-5111.

25. Perez, J.J.; Corcho, F.J.; Rubio-Martinez, J. Design of Peptidomimetics. In "Burger's Medicinal Chemistry, Drug discovery, and Development". 7th Edition. Abraham, D.J. and Rotella, D.P. (Eds.), Wiley and Sons, New York, 2010.

26. Ko, E.; Liu, J.; Perez, L. M.; Lu, G.; Schaefer, A.; Burgess, K. Universal Peptidomimetics. J. Am. Chem. Soc. 2011, 133, 462-477.

27. Liskamp, R. M. J.; Rijkers, D. T. S.; Kruijtzer, J. A. W.; Kemmink, J. Peptides and Proteins as a Continuing Exciting Source of Inspiration for Peptidomimetics. ChemBioChem 2011, 12, 1626 - 1653.

28. Ko, E.; Liu, J.; Burgess, K. Minimalist and Universal Peptidomimetics. Chem. Soc. Rev., 2011, 40, 4411-4421.

29. Avan, I.; Hall, C. D.; Katritzky, A. R. Peptidomimetics via Modifications of Amino Acids and Peptide Bonds. Chem. Soc. Rev., 2014, 43, 3575

30. Kosterlitz, H. W. and Waterfield, A. A. In vitro models in study of structure-activity-relationships of narcotic analgesics. Annu. Rev. Pharmacol. Toxicol., 1975, 15, 29-47.

31. Wu, Z.; Hruby, V. J. Backbone Alignment Modeling of the StructureActivity Relationships of Opioid Ligands. J. Chem. Inf. Model. 2011, 51, 1151-1164.

32. Filizola, M.; Centeno, N.; Perez, J.J. Computational Study of the Conformational Domains of Peptide T. J. Pept. Sci., 1997, 3, 85-92.

33. Centeno, N.; Perez, J.J. A Proposed Bioactive Form of Peptide T. J. Comput.-Aided Mol. Design, 1998, 12, 7-14.

34. Kim, K.-H.; Kim, N. D.; Seong, B.-L. Pharmacophore-Based Virtual Screening: a Review of Recent Applications. Expert Opin. Drug Discov. 2010, 5, 205-222.

35. Portoghese, P.S. Relationships between Stereostructure and Pharmacological Activities. Ann. Rev.Pharmacol. 1970, 10, 51-76. 
36. Fournier, A.; Couture, R.; Regoli, D.; Gendreau, M.; St-Pierre, S. Synthesis of Peptides by the SolidPhase Method. 7. Substance P and Analogues. J. Med. Chem. 1982; 25, 64-68.

37. Noda, M.; Teranishi, Y.; Takahashi, H.; Toyosato, M.; Notake, M.; Nakanishi, S.; Numa, S. Isolation and Structural Organization of The Human Preproenkephalin Gene. Nature 1982, 297, 431-434.

38. Dufresne, M.; Seva, C. and Fourmy, D. Cholecystokinin and Gastrin Receptors. Physiol. Rev. 2006, $686,805-847$.

39. Durani, S. Protein Design with L- and D-a-Amino Acids Structures as Alphabet. Acc. Chem Res. 2008, 41, 1301-1308.

40. Morrison, K. L.; Weiss, G. A. Combinatorial Alanine-Scanning. Curr. Opin. Chem. Biol. 2001, 5, $302-$ 307.

41. Sattler, M.; Liang, H.; Nettesheim, D.; Meadows, R.P.; Harlan, J.E.; Eberstadt, M.; Yoon, H.S.; Shuker, S.B.; Chang, B.S.; Minn, A.J.; Thompson, C.B.; Fesik, S.W. Structure of Bcl-XL-Bak Peptide Complex: Recognition Between Regulators of Apoptosis. Science 1997, 275, 983-986.

42. Chatterjee, J; Gilon, C.; Hoffman, A.; Kessler, H. N-methylation of peptides: a new perspective in medicinal chemistry. Acc. Chem. Res., 2008, 41, 1331-1342.

43. Zivec, M.; Jakopin, Z.; Gobec, S. Recent Advances in the Synthesis and Applications of Reduced Amide Pseudopeptides. Curr: Med. Chem., 2009, 16, 2289-2304.

44. Spatola, A. F. In Chemistry and Biochemistry of Amino Acids, Peptides and Proteins; Weinstein, B., Ed.; Marcel Dekker: NY, 1983; Vol. VII, p 267.

45. Patani, G. A.; LaVoie, E. J. Bioisosterism: A Rational Approach in Drug Design. Chem. Rev. 1996, 96, 3147-3176.

46. Langmuir, I. Isomorphism, Isosterism and Covalence. J. Am. Chem. Soc. 1919, 41, 1543-1559.

47. Burger, A. Isosterism and Bioisosterism in Drug Design. Prog.Drug Res. 1991, 37, 287-371.

48. Ghosh, Arun K.; Chapsal, B.D.; Weber, I. T.; Mitsuya, H. Design of HIV Protease Inhibitors Targeting Protein Backbone: An Effective Strategy for Combating Drug Resistance. Acc. Chem. Res. 2008, 41, 7886.

49. Choudhary, A.; Raines, R. T. An Evaluation of Peptide-Bond Isosteres. ChemBioChem 2011, 12, 1801-1807

50. Zhanga, W.; Li a, J.; Liua, L.-W.; Wanga, K.-R.; Songa, J.-J.; Yana, J.-X.; Li, Z.-Y.; Zhanga, B.-Z., Wang, R. A Novel Analog of Antimicrobial Peptide Polybia-MPI, with Thioamide Bond Substitution, Exhibits Increased Therapeutic Efficacy Against Cancer and Diminished Toxicity in Mice. Peptides 2010, 31, 1832-1838.

51. Wiberg, K. B.; Laidig, K. E. Barriers to Rotation Adjacent to Double Bonds. 3. The Carbon-Oxygen Barrier in Formic Acid, Methyl Formate, Acetic Acid, and Methyl Acetate. The Origin of Ester and Amide Resonance. J. Am. Chem. Soc.1987, 109, 5935 - 5943.

52. Hollstein, U. Actinomycin. Chemistry and Mechanism of Action. Chem. Rev. 1974, 74, 625-652. 
53. Ueda, H.; Nakajima, H.; Hori, Y. FR901228, a Novel Antitumor Bicyclic Depsipeptide Produced by Chromobacterium Violaceum No. 968. I. Taxonomy, Fermentation, Isolation, Physico-Chemical and Biological Properties, and Antitumor Activity. J. Antibio. 1994, 47, 301-310.

54. Nguyen, J.-T.; Hamada, Y.; Kimura, T.; Kiso, Y. Design of Potent Aspartic Protease Inhibitors to Treat Various Diseases. Arch. Pharm. Chem. Life Sci. 2008, 347, 523-535.

55. Torbeev, V. Y.; Mandal, K. ; Terechko, V. A.; Kent, S. B. H. Crystal Structure of Chemically Synthesized HIV-1 Protease and a Ketomethylene Isostere Inhibitor Based on the P2/NC Cleavage Site. Bioorg. Med. Chem. Lett.. 2008, 18, 4554-4557.

56. Gelb, M.H.; Svaren, J.P.; Abeles, R.H. Fluoro Ketone Inhibitors of Hydrolytic Enzymes. Biochemistry. 1985, 9;24, 1813-1817.

57. Gradman, A.; Schmieder, R.; Lins, R. Nussberger, J.; Chiang, Y.; Bedigian, M. Aliskiren, A Novel Orally Effective Renin Inhibitor, Provides Dose-Dependent Antihypertensive Efficacy and Placebo-Like Tolerability In Hypertensive Patients. Circulation 2005, 111, 1012-1018.

58. Rodriguez, M.; Lignon, M.-F.; Galas, M.-C.; Fulcrand, P.; Mendre, C.; Aumelas, A.; Laur, J.; Martinez, J. Synthesis and Biological Activities of Pseudopeptide Analogues of the C-Terminal Heptapeptide of Cholecystokinin. On the Importance of the Peptide Bonds. J. Med. Chem. 1987, 30, 1366-1373.

59. Sasaki, Y.; Murphy, W. A.; Heiman, M. L.; Lance, V. A.; Coy, D. H. Solid-Phase Synthesis and Biological Properties of $\Psi[\mathrm{CH}, \mathrm{NH}]$ Pseudopeptide Analogues of a Highly Potent Somatostatin Octapeptide. J. Med. Chem. 1987, 30, 1162-1166.

60. Coy, D.H.; Heinz-Erian, P.; Jiang, N.-Y., Sasaki, Y.; Taylor, J.; Moreau, J.-P.; Wolfrey, W.T.; Dardner, J.D.; Jensen, R.T. Probing Peptide Backbone Function In Bombesin - A Reduced Peptide-Bond Analog with Potent and Specific Receptor Antagonist Activity. J. Biol. Chem. 1988, 263, 5056-5060.

61. Xu, Guoyan G.; Zhang, Y.; Mercedes-Camacho, A. Y.; Etzkorn, F. A. A Reduced-Amide Inhibitor of Pin1 Binds In a Conformation Resembling a Twisted-Amide Transition State. Biochemistry 2011, 50, 9545-9550.

62. Black, W. C.; Bayly, C. I.; Davis, D. E.; Desmarais, S.; Falgueyret, J.-P.; Leger, S.; Li, C. S.; Masse, F.; McKay, D. J.; Palmer, J. T.; Percival, M. D.; Robichaud, J.; Tsou, N.; Zamboni, R. Trifluoroethylamines as Amide Isosteres In Inhibitors of Cathepsin K. Bioorg. Med. Chem. Lett. 2005, 15, 4741-4744.

63. Narumi, T.; Hayashi, R.; Tomita, K.; Kobayashi, K.; Tanahara, N.; Ohno, H.; Naito, T.; Kodama, E.; Matsuoka, M.; Oishi, S.; Fujii, N. Synthesis and Biological Evaluation of Selective CXCR4 Antagonists Containing Alkene Dipeptide Isosteres. Org. Biomol. Chem. 2010, 8, 616-621.

64. Allmendinger, T.; Felder, E.; Hungerbuhler, E. Fluoroolefin Dipeptide Isosteres .2. Enantioselective Synthesis of Both Antipodes of the Phe-Gly Dipeptide Mimic. Tetrahedron Lett. 1990, 31, 7301-7304

65. Inokuchi, E.; Oishi, S.; Kubo, T.; Ohno, H.; Shimura, K.; Matsuoka, M.; Fuji, N. Potent CXCR4 Antagonists Containing Amidine Type Peptide Bond Isosteres. ACS Med. Chem. Lett. 2011, 2, 477-480.

66. Chorev, M.; Goodman, M. A Dozen Years of Retro-Inverso Peptidomimetics. Acc. Chem. Res. 1993,26, 266-273.

67. Fletcher, M. D.; Campbell, M. M. Partially Modified Retro-Inverso Peptides: Development, Synthesis, and Conformational Behavior. Chem. Rev. 1998, 98, 763-795. 
68. Taylor, M.; Moore, S.; Mayes, J.; Parkin, E.; Beeg, M.; Canovi, M.; Gobbi, M.; Mann, D. M.; Allsop, D. Development of a Proteolytically Stable Retro-Inverso Peptide Inhibitor of Beta-Amyloid Oligomerization As a Potential Novel Treatment for Alzheimer's Disease. Biochemistry, 2010, 49, 3261-3272.

69. Simon, R. J.; Kania, R. S.; Zuckermann, R. N.; Huebner, V. D.; Jewell, D. A.; Banville, S.; Ng, S.; Wang, L.; Rosenberg, S.; Marlowe, C. K. Peptoids: A Modular Approach to Drug Discovery. Proc. Natl. Acad. Sci. USA 1992, 89, 9367 - 9371.

70. Kessler H. Peptoids: A New Approach to the Development of Pharmaceuticals. Angew. Chem. Int. Ed. Engl. 1993, 32, 543-544.

71. Socala, K. ; Nieoczym, D.; Rundfeldt, C.; Wlaz, P. Effects of Sarcosine, a Glycine Transporter Type 1 Inhibitor, In Two Mouse Seizure Models. Pharmacol. Reports. 2010, 62, 392-397.

72. Masip, I.; Perez-Paya, E.; Messeguer, A. Peptoids as Source of Compounds Eliciting Antibacterial Activity. Comb. Chem. High Throughput Screen. 2005, 8, 235-239.

73. Godballe, T.; Nilsson, L. L.; Petersen. P. D.; Jenssen, H. Antimicrobial $\beta$-Peptides and a-Peptoids. Chem Biol Drug Des. 2011, 77, 107-116.

74. Olsen, C. A. Peptoid-Peptide Hybrid Backbone Architectures. ChemBioChem 2010, 11, 152 - 160.

75. Lelais, G., Seebach, D. $\beta$-Amino Acids: Syntheses, Occurrence In Natural Products, and Components of $\beta$-Peptides. Biopolymers. 2004, 76, 206-243.

76. Schmitt M.A., Weisblum B., Gellman S.H. Unexpected Relationships Between Structure And Function In Alpha,Beta-Peptides: Antimicrobial Foldamers with Heterogeneous Backbones. J. Am. Chem. Soc., 2004, 126, 6848-6849.

77. Kohen, R.; Yamamoto, Y.; Cundy, K. C.; Ames, B. N. Antioxidant Activity of Carnosine, Homocarnosine, and Anserine Present In Muscle and Brain. Proc. Nat. Acad. Sci. 1988, 85, 3175-3179.

78. Hart, S.A.; Bahadoor, A.B.; Matthews, E.E.; Qiu, X.J.; Schepartz, A. Helix Macrodipole Control of Beta 3 Peptide 14-Helix Stability In Water. J. Am. Chem. Soc. 2003, 125, 4022-4023.

79. Baldauf, C.; Pisabarro, M.T. Stable Hairpins with Beta-Peptides: Route to Tackle Protein-Protein Interactions. J. Phys. Chem. B 2008, 112, 7581-7591.

80. Frederick, K. K.; Marlow, M. S.; Valentine, K. G.; Wand, A. J. Conformational Entropy In Molecular Recognition by Proteins. Nature, 2007, 448, 325-329.

81. Fischer, E. Einfluss der Configuration auf die Wirkung der Enzyme. Ber. Dtsch. Chem. Ges. 1894, 27, 2984-2993.

82. Koshland, D. E. Application of a Theory of Enzyme Specificity to Protein Synthesis. Proc. Natl. Acad. Sci. USA, 1958, 44, 98-104.

83. Trellet, M.; Melquiond, A. S. J.; Bonvin, A. M. J. J.. A Unified Conformational Selection and Induced Fit Approach to Protein-Peptide Docking. PLOS one 2013, 8, e58769.

84. Kouranov, A.; Xie, L.; de la Cruz, J.; Chen, L.; Westbrook,J.; Bourne, P.E.; Berman, H.M. The RCSB PDB Information Portal for Structural Genomics. Nucleic Acids Res. 2006, 34, D302-D305. 
85. Vanhee, P.; Reumers, J.; Stricher, F.; Baeten, L.; Serrano, L.; Schymkowitz, J.; Rousseau, F. Pepx: A Structural Database of Non-Redundant Protein-Peptide Complexes. Nucleic Acids Res. 2010, 38, D545D551

86. Vanhee, P.; Stricher, F.; Baeten, L.; Verschueren, E.; Lenaerts, T.; Serrano, L.; Rousseau, F.; Schymkowitz, J. Protein-Peptide Interactions Adopt the Same Structural Motifs as Monomeric Protein Folds. Structure. 2009, 17, 1128-1136.

87. Venkatesan K, Rual J-F, Vazquez A, Stelzl, U.; Lemmens, I.; Hirozane-Kishikawa, T. ; Hao, T.; Zenkner, M. ; Xin, X. ; Goh, K.; Yildirim, M. ; Simonis, N. ; Heinzmann, K.; Gebreab, F. ; Sahalie, J. M.; Cevik, S.; Simon, C. ; de Smet, A.-S.; Dann, E.; Smolyar, A.; Vinayagam, A.; Yu, H.; Szeto, D.; Borick, H.; Dricot, A.; Klitgord, N.; Murray, R. R.; Lin, C.; Lalowski, M.; Timm, J.; Rau, K.; Boone, C.; Braun, P.; Cusick, M.; Roth, F.; Hill, D.; Tavernier, J.; Wanker, E. E.; Barabasi, A.-L.; Vidal, M. An Empirical Framework for Binary Interactome Mapping. Nat. Methods. 2009, 6, 83-90.

88. Pauling, L. Nature of Forces between Large Molecules of Biological Interest. Nature 1948, 161, 707709

89. Wolfenden, R.; Kati, W. M. Testing the Limits of Protein Ligand-Binding Discrimination with TransitionState Analog Inhibitors. Acc. Chem. Res. 1991, 24, 209-215

90. Drag, M.; Salvesen, G. S. Emerging Principles in Protease-Based Drug Discovery. Nat. Rev. Drug Discov. 2010, 9, 690-701

91. Timmer, J. C.; Zhu, W.; Pop, C.; Regan, T.; Snipas, S. J.; Eroshkin, A. M.; Riedl, S. J.; Salvesen, G. S. Structural and Kinetic Determinants of Protease Substrates. Nat. Struct. Molec. Biol. 2009, 16, 1101-1109.

92. Yanevaa, R.; Schneeweissa, C.; Zachariasb, M.; Springer, S. Peptide Binding To MHC Class I And II Proteins: New Avenues From New Methods. Mol. Immunol. 2010, 47, 649-657

93. Hergeta, M.; Baldaufa, C.; Schölza, C.; Parceja, D.; Wiesmüllerb, K.-H.; Tampea, R.; Abelea, R.; Bordignon, E. Conformation of Peptides Bound To The Transporter Associated with Antigen Processing (TAP). Proc. Natl. Acad. Sci. USA, 2011, 108, 1349-1354

94. Wilson, I.A.; Stanfield, R.L. Antibody-Antigen Interactions: New Structures and New Conformational Changes. Curr. Opin. Struct. Biol. 1994, 4, 857-867.

95. 115. Sheriff, S.; Hendrickson, W.A. Structure of Myohemerythrin in The Azidomet State At 1.7/1.3 A Resolution. J. Mol. Biol. 1987, 197, 273-296.

96. 116. Stanfield, R.L.; Fieser, T.M.; Lerner, R.A.; Wilson, I.A. Crystal Structures of An Antibody To A Peptide And Its Complex With Peptide Antigen At 2.8 A. Science, 1990, 248, 712-719.

97. White, J. F.; Noinaj, N.; Shibata, Y.; Love, J.; Kloss, B.; Xu, F.; Gvozdenovic-Jeremic, J.; Shah, P.; Shiloach, J.; Tate, C. G.; Grisshammer, R. Structure of the Agonist-Bound Neurotensin Receptor. Nature, $2012,490,508-513$

98. Luca, S.; White, J. F.; Sohal, A. K.; Filippov, D. V.; Boom, J. H. van; Grisshammer, R.; Baldus, M. The Conformation of Neurotensin Bound to Its G Protein-Coupled Receptor. Proc. Natl. Acad. Sci. USA, 2003, 100, 10706-10711

99. Coutant, J.; Curmi, P. A.; Toma, F.; Monti, J.-P. NMR Solution Structure of Neurotensin In MembraneMimetic Environments: Molecular Basis for Neurotensin Receptor Recognition. Biochemistry 2007, 46, 5656-5663 
100.Lopez, J. J.; Shukla, A. K.; Reinhart, C.; Schwalbe, H.; Michel, H.; Glaubitz, C. The Structure of The Neuropeptide Bradykinin Bound to the Human G-Protein Coupled Receptor Bradykinin B2 as Determined by Solid- State NMR Spectroscopy. Angew. Chem. Int. Ed. 2008, 47, 1668 -1671

101.Blundell, C. D.; Packer, M. J.; Almond, A. Quantification of Free Ligand Conformational Preferences by NMR and Their Relationship to the Bioactive Conformation. Bioorg. Med. Chem. 2013, 21, 4976-4987.

102.Balaram, P. Non-Standard Amino Acids In Peptide Design and Protein Engineering. Curr. Opin. Struct. Biol. 1992, 2, 845-851.

103.White, C. J.; Yudin, A. K. Contemporary Strategies for Peptide Macrocyclization. Nat. Chem. 2011, 3 , 509-524.

104.Rizo, J.; Gierasch, L. M. Constrained Peptides: Models of Bioactive Peptides and Protein Substructures. Annu. Rev. Biochem. 1992, 61, 387-418.

105.Giordanetto, F.; Kihlberg, J. Macrocyclic Drugs and Clinical Candidates: What Can Medicinal Chemists Learn From Their Properties? J. Med. Chem. 2014, 57, 278-295.

106.Cardote, T. A. F.; Ciulli, A. Cyclic and Macrocyclic Peptides as Chemical Tools to Recognise Protein Surfaces and Probe Protein-Protein Interactions. ChemMedChem 2016, 11, 787 - 794.

107.Frost, J.R.; Smith, J. M.; Fasan, R. Design, Synthesis, and Diversification of Ribosomally Derived Peptide Macrocycles. Curr. Opin. Struct. Biol. 2013, 23, 571-580.

108.Levine, D. Vancomycin: A History. Clin Infect Dis. 2006, 42, S5-S12.

109.Borel, J.F. History of the Discovery of Cyclosporin and of Its Early Pharmacological Development. Wien. Klin. Wochenschr. 2002, 114, 433-437.

110.Itagaki, F.; Shigemori, H.; Ishibashi, M.; Nakamura, T.; Sasaki, T.; Kobayashi, J. Keramamide F, a New Thiazole-Containing Peptide from the Okinawan Marine Sponge Theonella Sp. J. Org. Chem. 1992, $57,5540-5542$

111.Welker, M.; Von Döhren, H. Cyanobacterial Peptides - Nature's Own Combinatorial Biosynthesis. FEMS Microbiol. Rev. 2006, 30, 530-563.

112.Müller, G.; Gurrath, M.; Kessler, H. Pharmacophore Refinement of gpllb/llla Antagonists Based on Comparative Studies of Antiadhesive Cyclic and Acyclic RGD Peptides. J. Comp-Aided Mol. Design 1994, 8, 709-730.

113.Goodman, S. L.; Hölzemann, G.; Sulyok, G. A. G.; Kessler, H. Nanomolar Small Molecule Inhibitors for $\alpha v \beta 6$, av $\beta 5$, and av $\beta 3$ Integrins, J. Med. Chem. 2002, 45, 1045-1051.

114.Veber, D. F.; Holly, F. W.; Nutt, R. F.; Bergstrand, S. J.; Brady,S. F.; Hirschmann, R.; Glitzer, M. S.; Saperstein, R. Highly Active Cyclic and Bicyclic Somatostatin Analogues of Reduced Ring Size. Nature 1979, 280, 512-514.

115.Veber, D. F.; Saperstein, R.; Nutt, R. F.; Freidinger, R. M.; Brady, S. F.; Curley, P.; Perlow, D. S.; Paleveda, W. J.; Colton, C. D.; Zacchei, A. G.; Tocco, D. J.; Hoff, D. R.; Vandlen, R. L.; Gerich, J. E.; Hall, L.; Mandarino, L.; Cordes, E. H.; Anderson, P. S.; Hirschmann, R. A Super Active Cyclic Hexapeptide Analog of Somatostatin. Life Sci. 1984, 34, 1371-1378. 
116.Fung, S; Hruby, V.J. Design of Cyclic and Other Templates For Potent And Selective Peptide a-MSH Analogues. Curr. Opin. Chem. Biol. 2005, 9, 352-358.

117.Gulyas, J.; Rivier, C.; Perrin, M.; Koerber, S.C.; Sutton, S.; Corrigan, A.; Lahrichi, S.L.; Craig, A.G.; Vale, W.W.; Rivier, J. Potent, Structurally Constrained Agonists and Competitive Antagonists of Corticotropin Releasing Factor (CRF). Proc. Natl. Acad. Sci. USA. 1995, 92, 10575-10579.

118. Shibukawa, M.; Miyake, A.; Eda, S.; Saito, Shingo. Determination of the Cis-Trans Isomerization Barriers of L-Alanyl-L-Proline In Aqueous Solutions and at Water/Hydrophobic Interfaces by On-Line Temperature-Jump Relaxation HPLC And Dynamic On-Column Reaction HPLC. Anal. Chem. 2015, 87, 9280-9287.

119. Lummis, S. C. R.; Beene, D. L.; Lee, L. W.; Lester, H. A.; Broadhurst, R. W.; Dougherty, D. A. CisTrans Isomerization at a Proline Opens the Pore of a Neurotransmitter-Gated Ion Channel. Nature 2005, 438, 248-252.

120. Wedemeyer, W. J.; Welker, E.; Scheraga, H. A. Proline Cis-Trans Isomerization and Protein Folding. Biochemistry 2002, 41, 14637-14644.

121. Ananthanarayanan, V.S.; Brahmachari, S. K.; Pattabiraman, N. Proline-Containing $\beta$-Turns In Peptides And Proteins: Analysis of Structural Data on Globular Proteins. Arch. Biochem. Biophys. 1984, 232, 482-495.

122. Degenkolba, T.; Bruckner, H. Peptaibiomics: Towards a Myriad of Bioactive Peptides Containing CaDialkylamino Acids? Chem. Biodivers. 2008, 5, 1817-1843

123. Toniolo, C.; Crisma, M.; Formaggio, F.; Peggion, C. Control of Peptide Conformation by the ThorpeIngold Effect (Ca-Tetrasubstitution). Biopolymers (Pept Sci). 2001, 60, 396-419.

124. Karle, I.; Balaram, P. Structural Characteristics of a-Helical Peptide Molecules Containing Aib Residues. Biochemistry, 1990, 29, 6747-6756.

125. Formaggio, F.; Crisma, M.; Rossi, P.; Scrimin, P.; Kaptein, B.; Broxterman, Q. B.; Kamphuis, J.; Toniolo, C. The First Water-Soluble 310 Helical Peptides. Chem. Eur. J. 2000, 6, 4498-4504.

126. Di Blasio, B.; Pavone, V.; Lombardi, A.; Pedone, C.; Benedetti, E. Non-Coded Residues as Building Blocks In the Design of Specific Secondary Structures: Symmetrically Di-Substituted Glycines And $\beta$ Alanine. Biopolymers. 1993, 33, 1037-1049.

127. Crisma, M.; Moretto, A.; Rainaldi, M.; Formaggio, F.; Broxterman, Q.Q.; Kaptein, B.; Toniolo, C. Crystal-State 3D-Structural Characterization of Novel 310-Helical Peptides. J. Peptide Sci. 2003, 9, 620637.

128. Jaun, B.; Tanaka, M.; Seiler, P.; Kuhnle, F. N. M.; Braun, C.; Seebach, D. Studies on the Conformation of Boc-Protected (S)-(+)-Isovaline Homopeptide Methyl Esters in the Solid State and in Solution. Liebigs Ann.1997, 1697- 1710.

129. Brackmann F.; de Meijere, A. Natural Occurrence, Syntheses, and Applications of CyclopropylGroup-Containing a-Amino Acids. 1.1-Aminocyclopropanecarboxylic Acid and Other 2,3-Methanoamino Acids. Chem. Rev. 2007, 107, 4493-4537.

130. Gomez-Catalan, J.; Alemán, C.; Perez, J.J. Conformational Profile of 1-Aminocyclopropanecarboxylic Acid. Theor. Chem. Acc., 2000, 103, 380-389. 
131. Tsang, J. W.; Schmied, B.; Nyfeler, R.; Goodman, M. Peptide Sweeteners. 6. Structural Studies on the C-Terminal Amino Acid of L- Aspartyl Dipeptide Sweeteners. J. Med. Chem. 1984, 27, 1663-1668

132. Evans, M. C.; Pradhan, A.; Venkatraman, S.; Ojala, W. H.; Gleason, W. B.; Mishra, R. K.; Johnson, R. L. Synthesis and Dopamine Receptor Modulating Activity of Novel Peptidomimetics of L-Prolyl-L-leucylglycinamide Featuring a,a-Disubstituted Amino Acids. J. Med. Chem. 1999, 42, 1441.

133. Chatelain, R. E.; Ghai, R. D.; Trapani, A. J.; Odorico, L. M.; Dardik, B. N.; De Lombaert, S.; Lappe, R. W.; Fink, C. A. Antihypertensive and Natriuretic Effects of CGS 30440, a Dual Inhibitor of AngiotensinConverting Enzyme and Neutral Endopeptidase 24.11. J. Pharmacol. Exp. Ther. 1998, 284, 974-982.

134. Ichihara, A.; Shiraishi, K.; Sato, H.; Sakamura, S.; Nishiyama, K.; Sakai, R.; Furusaki, A.; Matsumoto, T. Structure of Coronatine. J. Am. Chem. Soc. 1977, 99, 636-637.

135. Cativiela, C.; Díaz-de-Villegas, M. D. Stereoselective Synthesis of Quaternary a-Amino Acids. Part 2: Cyclic Compounds. Asymmetry. 2000, 11, 645-732.

136. Jimenez, A. I.; Cativiela, C.; Aubry, A.; Marraud, M. $\beta$-Turn Preferences Induced by 2,3 Methanophenylalanine Chirality J. Am. Chem. Soc. 1998, 120, 9452-9459.

137. Reichelt, A.; Martin, S. F. Synthesis and Properties of Cyclopropane-Derived Peptidomimetics. Acc. Chem. Res. 2006, 39, 433-442.

138. Malin, D.H. J.; Lake, R.; Payza, K.; Corriere, L. S.; Benson, T.M.; Garber, T. L.; Waller, M. L.; Luu, T.-A.; Kelley, R. S.; Smith, D. A.; Ho, K.-K.; Burgess, K. Enhanced Antiopiate Activity and Enzyme Resistance In Peptidomimetics of FMRFamide Containing (E)-2,3-Methanomethionine. Peptides. 1993, $14,731-734$.

139. Kuroda, Y.; Ueda, H.; Nozawa, H.; Ogoshi, H. Adamantyl Amino Acid as Y-Turn Inducer for Peptide. Tetrahedr. Lett. 1997, 38, 7901-7904.

140. Liu, J.; Obando, D.; Liao, V.; Lifa, T.; Codd, R. The Many Faces of the Adamantyl Group In Drug Design. Eur. J. Med. Chem. 2011, 46, 1949-1963

141. Coulter, A. W.; Lombardini, J. B.; Sufrin, J. R.; Talalay, P. Structural and Conformational Analogues of L-Methionine as Inhibitors of the Enzymatic Synthesis of S-Adenosyl-L-methionine. III. Carbocyclic and Heterocyclic Amino Acid. Mol. Pharmacol. 1974, 10, 319-334

142. Mathur, P.; Ramakumar, S.; Chauhan, V. S. Peptide Design Using Dehydro Amino Acids: From $\beta$ Turns to Helical Hairpins. Biopolymers (Pept Sci) 2004, 76, 150-161.

143. Jung, G. Lantibiotics - Ribosomally Synthesized Biologically-Active Polypeptides Containing Sulfide Bridges and Alpha-Beta-Didehydroamino Acids. Angew. Chem.Int. Ed. Eng. 1991, 30, 1051-1068.

144. Zhang, Q.; Yu, Y.; Vélasquez, J. E ; van der Donka, W. A. Evolution of Lanthipeptide Synthetases. Proc. Natl. Acad. Sci. USA. 2012, 109, 18361-18366.

145. Mishra, A.; Misra, A.; Sri Vaishnavi, T.; Thota, C.; Gupta, M. Ramakumar, S.; Chauhan, V. S. Conformationally Restricted Short Peptides Inhibit Human Islet Amyloid Polypeptide (hIAPP) Fibrillization. Chem. Commun., 2013, 49, 2688-2690.

146. Pathak, S.; Chauhan, V. S. Rationale-Based, De Novo Design of Dehydrophenylalanine-Containing Antibiotic Peptides and Systematic Modification in Sequence for Enhanced Potency. Antimicrob. Agents Chemother. 2011, 55, 2178-2188. 
147. Bach, T. M. H.; Takagi, H. Properties, Metabolisms, and Applications of L-Proline Analogues. Appl. Microbiol. Biotechnol. 2013, 97, 6623-6634.

148. Perlikowska, R.; Piekielna, J.; Mazur, M.; Koralewski , R.; Olczak, J.; do Rego, J.-C.; Fichna, J.; Modranka, J.; Janecki, T.; Janeck, A. Antinociceptive and Antidepressant-Like Action of Endomorphin-2 Analogs with Proline Surrogates In Position 2. Bioorg. Med. Chem. 2014, 22, 4803-4809.

149. Hodaka, K.; Kimura, T.; Ruben A.J.; Uemura, T.; Kamiya, M.; Kiso, A.; Okamoto, T.; Tsuchiya, Y.; Hayashi, Y.; Freire, E.; Kiso, Y. Antimalarial Activity Enhancement In Hydroxymethylcarbonyl (HMC) Isostere-Based Dipeptidomimetics Targeting Malarial Aspartic Protease Plasmepsin. Bioorg. Med. Chem. 2008, 16, 10049-10060.

150. Wadworth, A.N.; Brogden, R.N. Quinapril - A Review of Its Pharmacological Properties, and Therapeutic Efficacy In Cardiovascular Disorders. Drugs 1991, 41, 378-399.

151. Mosberg, H.I.; Hurst, R.; Hruby, V.J.; Gee, K.; Yamaura, H.I.; Galligan, J.J.; Burks, T.F. Bispenicillamine Enkephalins Possess Highly Improved Specificity toward $\delta$ Opioid Receptors. Proc. Natl.Acad. Sci. USA. 1983, 80, 5871-5874.

152. Hruby; V. J.; Li, G.; Haskell-Luevano, C.; Shenderovich, M. Design of Peptides, Proteins, and Peptidomimetics in Chi Space. Biopolymers. 1997, 43, 219-266.

153. Mosberg, H. I.; Omnaas, J. R.; Lomize, A.; Heyl, D. L.; Nordan, I.; Mousigian, C.; Davis, P.; Porreca, F. Development of a Model for the $\delta$-Opioid Receptor Pharmacophore. 2. Conformationally Restricted Phe3 Replacements in the Cyclic $\delta$ Receptor Selective Tetrapeptide Tyr-c[D-Cys-Phe-D-Pen]OH (JOM 13). J. Med. Chem. 1994, 37, 4384-4391.

154. Eid, C. N.; Nicas, T. I.; Mullen, D. L.; Loncharich, R. J.; Paschal, J. W. Design, Syntheses And Potentiating Activities Against Methicillin Resistant Staphylococcus Aureus of Cyclic Analogs of Ly301621. Bioorg. Med. Chem. Lett. 1997, 7, 2087-2092.

155. Ruiz-Gomez, G.; Tyndall, J.D.A.; Pfeiffer, B.; Abbenante, G.; Fairlie, D.P. Update 1 of: Over One Hundred Peptide-Activated G Protein-Coupled Receptors Recognize Ligands with Turn Structure. Chem. Rev. 2010, 110, PR1-PR41.

156. Freidinger, R.M.; Veber, D.F.; Perlow, D.; Brooks, J.R.; Saperstein, R. Bioactive Conformation of Luteinizing-Hormone-Releasing Hormone-Evidence from a Conformationally Constrained Analog. Science 1980, 210, 656-658.

157. Perdih, A.; Kikelj, D. The Application of Freidinger Lactams and Their Analogs In the Design of Conformationally Constrained Peptidomimetics. Curr. Med. Chem. 2006, 13, 1525-1556.

158. Freidinger, R. M. Design and Synthesis of Novel Bioactive Peptides and Peptidomimetics. J. Med. Chem. 2003, 46, 5553-5565.

159. Olson, G.L.; Voss, M.E.; Hill, D.E. Kahn, M.; Madison, V.S.; Cook, C.M. Design and Synthesis of a Protein $\beta$-Turn Mimetic. J. Am. Chem. Soc. 1990, 112, 323-333.

160. Yanagisawa, H.; Ishihara, S.; Ando, A.; Kanazaki, T.; Miyamoto, S.; Koike, H.; lijima, Y.; Oizumi, K.; Matsushita, Y.; Hatat, T. Angiotensin-Converting Enzyme Inhibitors: Perhydro-l,4-thiazepin-li one Derivatives. J.Med.Chem.1987, 30, 1984-1991.

161. Trabocchi, A.; Scarpi, D.; Guarna, A. Structural Diversity of Bicyclic Amino Acids. Amino Acids. 2008, $34,1-24$. 
162. Peng, H.; Carrico, D.; Thai, V.; Blaskovich, M.; Bucher, C.; Pusateri, E. E.; Sebti, S. M.; Hamilton, A. D. Synthesis and Evaluation of Potent, Highly-Selective, 3-aryl-piperazinone Inhibitors of Protein Geranylgeranyltransferase-I. Org. Biomol. Chem. 2006, 4, 1768-1784.

163. Estiarte, M. A.; Diez, A.; Rubiralta, M.; Jackson, R. F. W. Synthesis of a 3-Aminopiperidin-2,5-dione as a Conformationally Constrained Surrogate of the Ala-Gly Dipeptide. Tetrahedron. 2001, 57, 157-161.

164. Borthwick, A. D. 2,5-Diketopiperazines: Synthesis, Reactions, Medicinal Chemistry and Bioactive Natural Products. Chem. Rev. 2012, 112, 3641-3716

165. Tan, R. X.; Jensen, P. R.; Williams, P. G.; Fenical, W. Isolation and Structure Assignments of Rostratins A-D, Cytotoxic Disulfides Produced by the Marine-Derived Fungus Exserohilum rostratum. J. Nat. Prod. 2004, 67, 1374-1382.

166. Borthwick, A. D.; Davies, D. E.; Exall, A. -M.; Livermore, D. G.; Sollis, S. L.; Nerozzi, F.; Allen, M. J.; Perren, M., Shabbir, S. S.; Woollard, P. M.; Wyatt, P. G. 2,5-Diketopiperazines as Potent, Selective, and Orally Bioavailable Oxytocin Antagonists. 2. Synthesis, Chirality, and Pharmacokinetics. J. Med. Chem. $2005,48,6956-6969$.

167. Yamazaki, Y.; Tanaka, K.; Nicholson, B.; Deyanat-Yazdi, G.; Potts, B.; Yoshida, T.; Oda, A.; Kitagawa, T.; Orikasa, S.; Kiso, Y.; Yasui, H.; Akamatsu, M.; Chinen, T.; Usui, T.; Shinozaki, Y.; Yakushiji, F.; Miller, B. R.; Neuteboom, S.; Palladino, M.; Kanoh, K.; Lloyd, G. K.; Hayashi, Y. Synthesis and Structure-Activity Relationship Study of Antimicrotubule Agents Phenylahistin Derivatives with a Didehydropiperazine-2,5-dione Structure. J. Med. Chem. 2012, 55, 1056-1071.

168. Ramanathan, S.K.; Keeler, J.; Lee, H.-L.; Reddy, D. S.; Lushington, G.; Aube, J. Modular Synthesis of Cyclic Peptidomimetics Inspired by $\mathrm{Y}$-Turns. Org. Lett. 2005, 7, 1059-1062.

169. Hulten, J.; Bonham, N. M.; Nillroth, U.; Hansson, T.; Zuccarello, G.; Bouzide, A.; Aqvist, J.; Classon, B.; Danielson, U. H.; Karlen, A. Kvarnstrom, I.; Samuelsson, B.; Hallberg, A. Cyclic HIV-1 Protease Inhibitors Derived from Mannitol: Synthesis, Inhibitory Potencies, and Computational Predictions of Binding Affinities. J. Med. Chem. 1997, 40, 885-897.

170. Lena, G.; Lallemand, E.; Gruner, A. C.; Boeglin, J.; Roussel, S.; Schaffner, A.-P.; Aubry, A.; Franetich, J.-F.; Mazier, D.; Landau, I.; Briand, J.-P.; Didierjean, C.; Renia, L.; Guichard, G. 1,3,5Triazepan-2,6-diones as Structurally Diverse and Conformationally Constrained Dipeptide Mimetics: Identification of Malaria Liver Stage Inhibitors from a Small Pilot Library. Chem. Eur. J. 2006, 12, 8498 8512.

171. Hanessian, S.; McNaughton-Smith, G.; Lombart, H.-G.; Lubell, W.D. Design and Synthesis of Conformationally Constrained Amino Acids as Versatile Scaffolds and Peptide Mimetics. Tetrahedron. 1997, 38, 12789-12854.

172. Cluzeau, J.; Lubell, W.D. Design, Synthesis, and Application of Azabicyclo[X.Y.0]alkanone Amino Acids as Constrained Dipeptide Surrogates and Peptide Mimics. Peptide Sci. 2005, 80, 98-150.

173. Diguarher, T. L.; Ortuno, J.-C.; Shanks, D.; Guilbaud, N.; Pierre, A.; Raimbaud, E.; Fauchere, J.-L.; Hickman, J. A.; Tucker, G. C.; Casara, P. J. Synthesis of N,N'-disubstituted 3-aminobenzo[c] and [d]azepin-2-ones as Potent and Specific Farnesyl Transferase Inhibitors. Bioorg. Med. Chem. Lett. $2004,14,767-771$.

174. Slade, J.; Stanton, J. L.; Ben-David, D.; Mazzenga, G. C. Angiotensin Converting Enzyme Inhibitors: 1,5-Benzothiazepine Derivatives. J. Med. Chem. 1985, 28, 1517-1521. 
175. Guerrini, G.; Ciciani, G. Benzodiazepine Receptor Ligands: A Patent Review (2006-2012). Expert Opin. Ther. Pat. 2013, 23, 843-866.

176. Arosio, D.; Belvisi, L.; Colombo, L.; Colombo, M.; Invernizzi, D.; Manzoni, L.; Potenza, D.; Serra, M.; Castorina, M.; Pisano, C.; Scolastico, C. A Potent Integrin Antagonist From a Small Library of Cyclic RGD Pentapeptide Mimics Including Benzyl-Substituted Azabicycloalkane Amino Acids. ChemMedChem. 2008, 3, 1589-1603.

177. St. Charles, R.; Matthews, J. H.; Zhang, E.; Tulinsky, A. Bound Structures of Novel P3-P1' $\beta$-Strand Mimetic Inhibitors of Thrombin. J. Med. Chem. 1999, 42, 1376-1383

178. Flynn, G.A., Beight, D.W.; Mehdi, S.; Koehl, J.R.; Giroux, E.L.; French, J.F.; Hake, P.W.; Dage, R.C. Application of A Conformationally Restricted Phe-Leu Dipeptide Mimetic to the Design of a Combined Inhibitor of Angiotensin I-Converting Enzyme And Neutral Endopeptidase 24.11. J. Med. Chem. 1993, 36, 2420-2423.

179 Bhagwanth, S.; Mishra, R. K.; Johnson, R. L. Development of Peptidomimetic Ligands of Pro-LeuGly-NH2 As Allosteric Modulators of the Dopamine D2 Receptor. Beilstein J. Org. Chem. 2013, 9, 204214.

180. Ressurreição, A. S. M.; Delatouche, R.; Gennari, C.; Piarulli, U. Bifunctional 2,5-Diketopiperazines as Rigid Three-Dimensional Scaffolds in Receptors and Peptidomimetics. Eur. J. Org. Chem. 2011, 217-228

181. Rai, R.; Raghothama, S.; Balaram, P. Design of a Peptide Hairpin Containing a Central ThreeResidue Loop. J. Am. Chem. Soc. 2006, 128, 2675-2681.

182. Robinson, J.A. The Design, Synthesis and Conformation of Some New $\beta$-Hairpin Mimetics: Novel Reagents for Drug and Vaccine Discovery. SynLett 2000, 429-441.

183. Srinivas, N.; Moehle, K.; Abou-Hadeed, K.; Obrecht, D.; Robinson, J. A. Biaryl Amino Acid Templates In Place of D-Pro-L-Pro In Cyclic $\beta$-Hairpin Cationic Antimicrobial Peptidomimetics. Org. Biomol. Chem. 2007, 5, 3100-3105.

184. Wu, C.-F.; Zhao, X.; Lan, W.-X.; Cao, C.; Liu, J.-T.; Jiang, X.-K., Li, Z.-T. A 1,4-Diphenyl-1,2,3Triazole-Based $\beta$-Turn Mimic Constructed by Click Chemistry. J. Org. Chem. 2012, 77, 4261-4270.

185. Tsang, K. Y.; Diaz, H.; Graciani, N.; Kelly, J. W. Hydrophobic Cluster Formation Is Necessary for Dibenzofuran-Based Amino Acids to Function as $\beta$-Sheet Nucleators. J. Am. Chem. Soc. 1994,116, 39884005 .

186. Kemp, D. S.; Li, Z. Q. 2-Amino-2'-carboxydiphenylacetylenes as $\beta$-Turn Mimetics. Synthesis and Conformational Properties. Tetrahedron Lett. 1995, 36, 4175-4178.

187. Feigel, M. 2,8-Dimethyl-4-( carboxymethyl)-6- (aminomethy1)phenoxathiin S-Dioxide: An Organic Substitute for the $\beta$-Turn in Peptides? J. Am. Chem. Soc. 1986, 108, 182-183.

188. Merabet, N.; Dumond, J.; Collinet, B.; Van Baelinghem, L.; Boggetto, N.; Ongeri, S.; Ressad, F.; Reboud-Ravaux, M.; Sicsic, S. New Constrained "Molecular Tongs" Designed To Dissociate HIV-1 Protease Dimer. J. Med. Chem. 2004, 47, 6392-6400.

189. Suich, D. J.; Mousa, S. A.; Singh, G.; Liapakis, G.; Reisine, T.; DeGrado, W. F. TemplateConstrained Cyclic Peptide Analogues of Somatostatin: Subtype-Selective Binding to Somatostatin Receptors and Antiangiogenic Activity. Bioorg. Med. Chem. 2000, 8. 2229-2241. 
190. Nowick, J. S.; Smith, E. M.; Noronha, G. Molecular Scaffolds. 3. An Artificial Parallel $\beta$-Sheet. J. Org. Chem. 1995,60, 7386-7387.

191. Ulysse Jr, L. G.; Chmielewski, J. A Light-Activated $\beta$-Turn Scaffold within a Somatostatin Analog: NMR Structure and Biological Activity. Chem. Biol. Drug Des. 2006, 67, 127-136.

192. Ross, N. T.; Katt, W. P.; Hamilton, A. D. Synthetic Mimetics of Protein Secondary Structure Domains. Phil. Trans. R. Soc. A. 2010, 368, 989-1008.

193. Mandal, D.; Shirazi, A. N.; Parang, K. Self-Assembly of Peptides to Nanostructures. Org. Biomol. Chem. 2014, 12, 3544-3561.

194. Azzarito, V.; Long, K.; Murphy, N. S.; Wilson, A. J. Inhibition of a-helix-mediated Protein-Protein Interactions Using Designed Molecules. Nat. Chem. 2013, 5, 161-173.

195. Pace, C. N.; Scholtz, J. M. A Helix Propensity Scale Based On Experimental Studies of Peptides and Proteins. Biophys. J. 1998, 75, 422-427.

196. Klein, M. A. Stabilized Helical Peptides: A Strategy to Target Protein-Protein Interactions. ACS Med. Chem. Lett. 2014, 5, 838-839

197. Marshall, G.R.; Hodgkin, E.E.; Langs, D.A.; Smith, G.D.; Zabrocki, J.;Leplawy, M.T. Factors Governing Helical Preference of Peptides Containing Multiple a,a-Dialkyl Amino Acids. Proc. Natl. Acad. Sci. USA. 1990, 87, 487-491

198. Cheng, R. P.; Gellman, S. H.; DeGrado, W. F. $\beta$-Peptides: From Structure to Function. Chem. Rev. 2001, 101, 3219-3232.

199. Kritzer, J. A.; Lear, J. D.; Hodsdon, M. E.; Schepartz, A. Helical $\beta$-Peptide Inhibitors of the p53-hDM2 Interaction. J. Am. Chem. Soc. 2004, 126, 9468-9469.

200. Doig, A. J.; Baldwin, R. L. N- and C-capping Preferences for All 20 Amino Acids in a-Helical Peptides. Protein Sci. 1995, 4, 1325-1336.

201. Bang, D. ; Gribenko, A. V.; Tereshko, V.; Kossiakoff, A. A.; Kent, S. B.; Makhatadze, G. I. Dissecting The Energetics of Protein a-Helix C-Cap Termination Through Chemical Protein Synthesis. Nat. Chem. Biol. 2006, 2, 139-143.

202. Muñoz, V.; Blanco, F. J.; Serrano, L. The Hydrophobic-Staple Motif and a Role for Loop-Residues In Alpha-Helix Stability And Protein Folding. Nature Struct. Mol. Biol. 1995, 2, 380 - 385.

203. Aurora, R.; Srinivasan, R.; Rose, G. D. Rules for Helix Termination by Glycine. Science, 1994, 264 , 1126-1129.

204. Viguera, A. R.; Serrano, L. Experimental Analysis of the Schellman Motif. J. Mol. Biol. 1995, 251, 150-160.

205. Prieto, J.; Serrano, L. C-capping and Helix Stability: The Pro C-capping Motif. J. Mol. Biol. 1997, 274, 276-288.

206. Che, Y.; Brooks, B.R.; Marshall, G.R. Development of Small Molecules Designed To Modulate Protein-Protein Interactions. J. Comput. Aided Des. 2006, 20, 109-130.

207. Condon, S. M.; Morize, I.; Darnbrough, S.; Burns, C. J.; Miller, B. E.; Uhl, J.; Burke, K.; Jariwala, N.; Locke, K.; Krolikowski, P.H.; Kumar, N. V.; Labaudiniere; R. F. The Bioactive Conformation of Human 
Parathyroid Hormone. Structural Evidence for the Extended Helix Postulate. J. Am. Chem. Soc. 2000, $122,3007-3014$

208. Patgiri, A.; Jochim, A.L.; Arora, P.S. A Hydrogen Bond Surrogate Approach for Stabilization of Short Peptide Sequences In A-Helical Conformation. Acc. Chem. Res. 2008, 41, 1289-1300.

209. Walensky, L. D.; Bird, G. H. Hydrocarbon-Stapled Peptides: Principles, Practice, and Progress. J. Med. Chem. 2014, 57, 6275-6288

210. Walensky, L. D.; Kung, A. L.; Escher, I.; Malia, T. J.; Barbuto, S.; Wright, R. D.; Wagner, G.; Verdine, G. L.; Korsmeyer, S. J. Activation of Apoptosis in vivo by a Hydrocarbon-Stapled BH3 Helix. Science $2004,305,1466-1470$.

211. Bernal, F.; Tyler, A. F.; Korsmeyer, S. J.; Walensky, L. D.; Verdine, G. L. Reactivation of The p53 Tumor Suppressor Pathway By A Stapled p53 Peptide. J. Am. Chem. Soc. 2007. 129, 2456-2457.

212. Moellering, R. E.; Cornejo, M.; Davis, T. N.; Del Bianco, C.; Aster, J. C.; Blacklow, S. C.; Kung, A. L.; Gilliland, D. G.; Verdine, G. L.; Bradner, J. E. Direct Inhibition of The NOTCH Transcription Factor Complex. Nature. 2009, 462, 182-188.

213. Phillips, C.; Roberts, L. R.; Schade, M.; Bazin, R.; Bent, A.; Davies, N. L.; Moore, R.; Pannifer, A. D.; Pickford, A. R.; Prior, S. H.; Read, C. M.; Scott, A.; Brown, D. G.; Xu, B.; Irving, S. L. Design and Structure of Stapled Peptides Binding to Estrogen Receptors. J. Am. Chem. Soc. 2011, 133, 9696-9699.

214. Bird, G. H.; Madani, N.; Perry, A. F.; Princiotto, A. M.; Supko, J. G.; He, X.; Gavathiotis, E.; Sodroski, J. G.; Walensky, L. D. Hydrocarbon Double-Stapling Remedies the Proteolytic Instability of a Lengthy Peptide Therapeutic. Proc. Natl. Acad. Sci. U.S.A. 2010, 107, 14093-14098.

215. Davis, J. M.; Tsoub, L. K.; Hamilton, A. D. Synthetic Non-Peptide Mimetics of a-Helices. Chem. Soc. Rev., 2007, 36, 326-334

216. Madala, P. K.; Tyndall, J. D. A., Nall, T.; Fairlie. D. P. Update 1 of: Proteases Universally Recognize Beta Strands In Their Active Sites. Chem. Rev. 2010, 110, PR1-PR31.

217. Takahashi, T.; Mihara, H. Peptide and Protein Mimetics Inhibiting Amyloid $\beta$-Peptide Aggregation. Acc. Chem. Res. 2008, 41, 1309-1318.

218 Loughlin, W. A.; Tyndall, J. D. A.; Glenn, M. P.; Hill, T. A.; Fairlie, D. P. Update 1 of: Beta-Strand Mimetics. Chem. Rev. 2010, 110, PR32-PR68.

219. Marsault, E.; Peterson, M. L. Macrocycles Are Great Cycles: Applications, Opportunities, and Challenges of Synthetic Macrocycles in Drug Discovery. J. Med. Chem. 2011, 54, 1961-2004

220. Reid, R. C.; March, D. R.; Dooley, M. J.; Bergman, D. A.; Abbenante, G.; Fairlie, D. P. A Novel Bicyclic Enzyme Inhibitor as a Consensus Peptidomimetic for the Receptor-Bound Conformations of 12 Peptidic Inhibitors of HIV-1 Protease. J. Am. Chem. Soc. 1996, 118, 8511-8517.

221. Kase, H.; Kaneko, M.; Yamada, K. K-13, A Novel Inhibitor of Angiotensin I Converting Enzyme Produced By Micromonospora Halophytica Subsp. Exilisia. I. Fermentation, Isolation and Biological Properties. J. Antibiot. (Tokyo) 1987, 40, 450-454.

222. Sano, S.; Ikai, K.; Katayama, K.; Takesako, K.; Nakamura, T.; Obayashi, A.; Ezure, Y.; Enomoto, H. OF4949, New Inhibitors of Aminopeptidase B. II. Elucidation of Structure. J. Antibiot. (Tokyo) 1986, 39, 1685-1696. 
223. Nowick, J. S.; Holmes, D. L.; Mackin, G.; Noronha, G.; Shaka, A. J.; Smith, E. M. An Artificial ß-Sheet Comprising a Molecular Scaffold, a $\beta$-Strand Mimic, and a Peptide Strand. J. Am. Chem. Soc. 1996, 118, 2764-2765.

224. Phillips, S.T.; Blasdel, L. K.; Bartlett, P. A. @-Tides as Reporters for Molecular Associations. J. Am. Chem.Soc. 2005, 127, 4193-4198.

225. Hammond, M. C.; Bartlett, P. A. Synthesis of Amino Acid-Derived Cyclic Acyl Amidines for Use in $\beta$ Strand Peptidomimetics. J. Org. Chem. 2007, 72, 3104-3107.

226. Wathen, B.; Jia, Z. Protein $\beta$-Sheet Nucleation Is Driven by Local Modular Formation. J Biol Chem. 2010, 285, 18376-18384.

227. Robinson, J. A. Protein Epitope Mimetics In The Age of Structural Vaccinology. J. Pept. Sci. 2013, 19, 127-140.

228. Fuller, A. A.; Du, D.; Liu, F.; Davoren, J. E.; Bhabha, G.; Kroon, G.; Case, D. A.; Dyson, H. J.; Powers, E. T.; Wipf, P.; Gruebele, M.; Kelly, J. W. Evaluating $\beta$-Turn Mimics as $\beta$-Sheet Folding Nucleators. Proc. Natl. Acad. Sci. USA 2009, 106, 11067-11072

229. Smith, C. K.; Regan, L. Construction and Design of $\beta$-Sheets. Acc. Chem. Res. 1997, 30, 153-161.

230. Munoz, V.; Thompson, P. A.; Hofrichter, J.; Eaton, W. A. Folding Dynamics and Mechanism of $\beta$ Hairpin Formation. Nature 1997, 390, 196-199.

231. Phillips, S. T.; Piersanti, G.; Bartlett, P. A. Quantifying Amino Acid Conformational Preferences And Side-Chain-Side-Chain Interactions in $\beta$-Hairpins. Proc. Natl. Acad. Sci. USA 2005, 102, 13737-13742.

232. Almeida, A. M.; Li, R.; Gellman, S. H. Parallel $\beta$-Sheet Secondary Structure Is Stabilized and Terminated by Interstrand Disulfide Cross-Linking. J. Am. Chem.Soc. 2012, 134, 75-78.

233. Wu, B.; Chien, E.Y.; Mol, C.D.; Fenalti, G.; Liu, W.; Katritch, V.; Abagyan, R.; Brooun, A.; Wells, P.; Bi, FC.; Hamel, D. J.; Kuhn P.; Handel, T. M.; Cherezov, V.; Stevens, R. C. Structures of the CXCR4 Chemokine GPCR With Small-Molecule And Cyclic Peptide Antagonists. Science 2010, 330, 1066-1071.

234. Robinson, J.A. $\beta$-Hairpin Peptidomimetics: Design, Structures and Biological Activities. Acc. Chem Res. 2008, 41, 1278-1288.

235. Nair, R. V.; Baravkar, S. B.; Ingole, T. S.; Sanjayan, G. J. Synthetic Turn Mimetics And Hairpin Nucleators: Quo Vadimus? Chem. Commun., 2014, 50,13874-13884.

236. Farmer, P. S. Bridging the Gap between Bioactive Peptides and Nonpeptides: Some Perspectives in Design. In Drug Design; Ariens, E. J., Ed.; Academic: New York, 1980; pp 119-143.

237. Belanger, P. C.; Dufresne, C. Preparation of exo-6-Benzyl-exo-2-(m-Hydroxyphenyl)- 1Dimethylaminomethylbicyclo[2.2.2]octane. A Non-Peptide Mimic of Enkephalins. Can. J. Chem. 1986, 64, 1514-1520.

238. Hirschmann, R. F.; Nicolaou, K. C.; Angeles, A. R.; Chen, J. S.; Smith III A. B. The B-D-Glucose Scaffold as a $\beta$-Turn Mimetic. Acc. Chem. Res. 2009, 42, 1511-1520.

239. Garland, S. L.; Dean, P. M. Design Criteria For Molecular Mimics of Fragments of The $\beta$-turn. 1. Ca Atom Analysis. J. Comput. Aided Mol. Des. 1999, 13, 469-483. 
240. Webb, T. R.; Venegas, R. E.; Wang, J.; Deschenes, A. Generation of New Synthetic Scaffolds Using Framework Libraries Selected and Refined via Medicinal Chemist Synthetic Expertise. J. Chem. Inf. Model. 2008, 48, 882-888.

241. Whitby, L.R.; Boger, D.L. Comprehensive Peptidomimetic Libraries Targeting Protein-Protein Interactions. Acc. Chem. Res. 2012, 45, 1698-1709.

242. Kim, J.; Lee, W. S.; Koo, J.; Lee, J.; Park, S.B. Synthesis and Library Construction of Privileged Tetra-Substituted $\Delta 5$-2-Oxopiperazine as $\beta$-Turn Structure Mimetics. ACS Comb. Sci. 2014, 16, 24-32.

243. Chianelli, D.; Kim, Y.-C.; Lvovskiy, D.; Webb, T. R. Application of a Novel Design Paradigm to Generate General Nonpeptide Combinatorial Scaffolds Mimicking Beta Turns: Dynthesis of Ligands for Domatostatin Receptors. Bioorg. Med. Chem. 2003, 11, 5059-5068.

244. Orner, B. P.; Ernst, J. T.; Hamilton, A. D. Toward proteomimetics: Terphenyl derivatives as structural and functional mimics of extended regions of a a-helix. J. Am. Chem. Soc. 2001, 123, 5382-5383.

245. Yin, H.; Lee, G.-i.; Sedey, K.A.; Kutzki, O.; Park, H.S.; Orner, B.P.; Ernst, J.T.; Wang, H.-G.; Sebti, S.M.; Hamilton, A. D. Terphenyl-based bak BH3 alpha-Helical Proteomimetics As Low-Molecular-Weight Antagonists of Bcl-X-L. J. Am. Chem. Soc. 2005, 127, 10191-10196.

246. Yin, H.; Lee, G.I.; Sedey, K. A.; Rodriguez, J.M.; Wang, H.G.; Sebti, S.M.; Hamilton, A.D. Terephthalamide Derivatives As Mimetics of Helical Peptides: Disruption Of The Bcl-x(L)/Bak Interaction. J Am Chem Soc. 2005, 127, 5463-5468.

247. Nevola, L., Ross, N. T.; Hamilton, A. D. Synthetic Inhibitors of Extended Helix-Protein Interactions Based On A Biphenyl 4,4'-Dicarboxamide Scaffold. ChemBioChem. 2009, 10, 829-833.

248. Huc, I. Aromatic Oligoamide Foldamers. Eur. J. Org. Chem. 2004, 17-29.

249. Qian, Y.; Blaskovich, M. A.; Saleem, M.; Seong, C. M.; Wathen, S. P.; Hamilton, A. D.; Sebti, S. M. Design and Structural Requirements of Potent Peptidomimetic Inhibitors of p21ras Farnesyltransferase. J. Biol. Chem. 1994, 269, 12410-12413.

250. Burns, C. J.; Guitton, J.-D.; Baudoin, B.; Lelievre, Y.; Duchesne, M.; Parker, F.; Fromage, N.; Commercon, A. Novel Conformationally Extended Naphthalene-Based Inhibitors of Farnesyltransferase. J. Med. Chem. 1997, 40, 1763-1767.

251. Sutherell, C. L.; Thompson, S.; Scott, R. T. W.; Hamilton, A. D. Aryl-Linked Imidazolidin-2-Ones as Non-Peptidic $\beta$-Strand Mimetics. Chem. Commun., 2012, 48, 9834-9836.

252. Kemp, D. S.; Bowen, B. R.; Muendel, C. C. Synthesis and Conformational Analysis of EpindolidioneDerived Peptide Models for $\beta$-Sheet Formation. J. Org. Chem. 1990, 55, 4650-4657.

253. Smith III, A. B.; Charnley, A. K.; Hirschmann, R. Pyrrolinone-Based Peptidomimetics. "Let the Enzyme or Receptor be the Judge". Acc. Chem. Res. 2010, 44, 180-193.

254. Nowick, J. S.; Chung, D. M.; Maitra, K.; Maitra, S.; Stigers, K. D.; Sun, Y. An Unnatural Amino Acid that Mimics a Tripeptide -Strand and Forms -Sheet like Hydrogen-Bonded Dimers. J. Am. Chem. Soc. 2000, 122, 7654-7661.

255. Nowick, J. S. Exploring $\beta$-Sheet Structure and Interactions with Chemical Model Systems. Acc. Chem. Res. 2008, 41, 1319-1330. 
256. Lingard, H.; Han, J. T.; Thompson, A. L.; Leung, I. K. H.; Scott, R. T. W.; Thompson, S.; Hamilton, A. D. Diphenylacetylene-Linked Peptide Strands Induce Bidirectional $\beta$-Sheet Formation. Angew. Chem. Int. Ed. 2014, 53, $3650-3653$. 
Table1. Results of the Ala scan on the hexadecapeptide Gly-Gln-Val-Gly-Arg-Gln-Leu-Ala-lle-Ile-Gly-AspAsp-lle-Asn-Arg, a segment of the Bak-BH3 domain with inhibitory capacity of the protein Bcl-xL. Residues are represented with the one letter code [41].

$\begin{array}{ll}\text { Peptide Sequence } & \mathrm{K}_{\mathrm{D}}(\mu \mathrm{M}) \\ \text { GQVGRQLAIIGDDINR } & 0.34 \pm 0.03 \\ \text { GQAGRQLAIIGDDINR } & 15 \pm 3 \\ \text { GQVGAQLAIIGDDINR } & 3.3 \pm 1 \\ \text { GQVGRQAAIIGDDINR } & 270 \pm 90 \\ \text { GQVGRQLAAIGDDINR } & 1.0 \pm 0.2 \\ \text { GQVGRQLAIAGDDINR } & 17 \pm 6 \\ \text { GQVGRQLAIIADDINR } & 0.5 \pm 0.1 \\ \text { GQVGRQLAIIGADINR } & 41 \pm 4 \\ \text { GQVGRQLAIIGDAINR } & 0.14 \pm 0.02 \\ \text { GQVGRQLAIIGDDANR } & 93 \pm 20\end{array}$


Figure 1. Two different approaches to design peptidomimetics: a medicinal chemistry approach, where parts of the peptide are successively replaced by non-peptide moieties until a non-peptide molecule is obtained. Alternatively, there is a biophysical approach, where a hypothesis of the bioactive form of the peptide is sketched and a pharmacophore is developed. Peptidomimetics are designed based on the use of diverse scaffolds to attach different chemical moieties for pharmacophore fulfillment or are discovered from virtual screening suing the pharmacophore as query.

\section{PEPTIDOMIMETICS DESIGN}

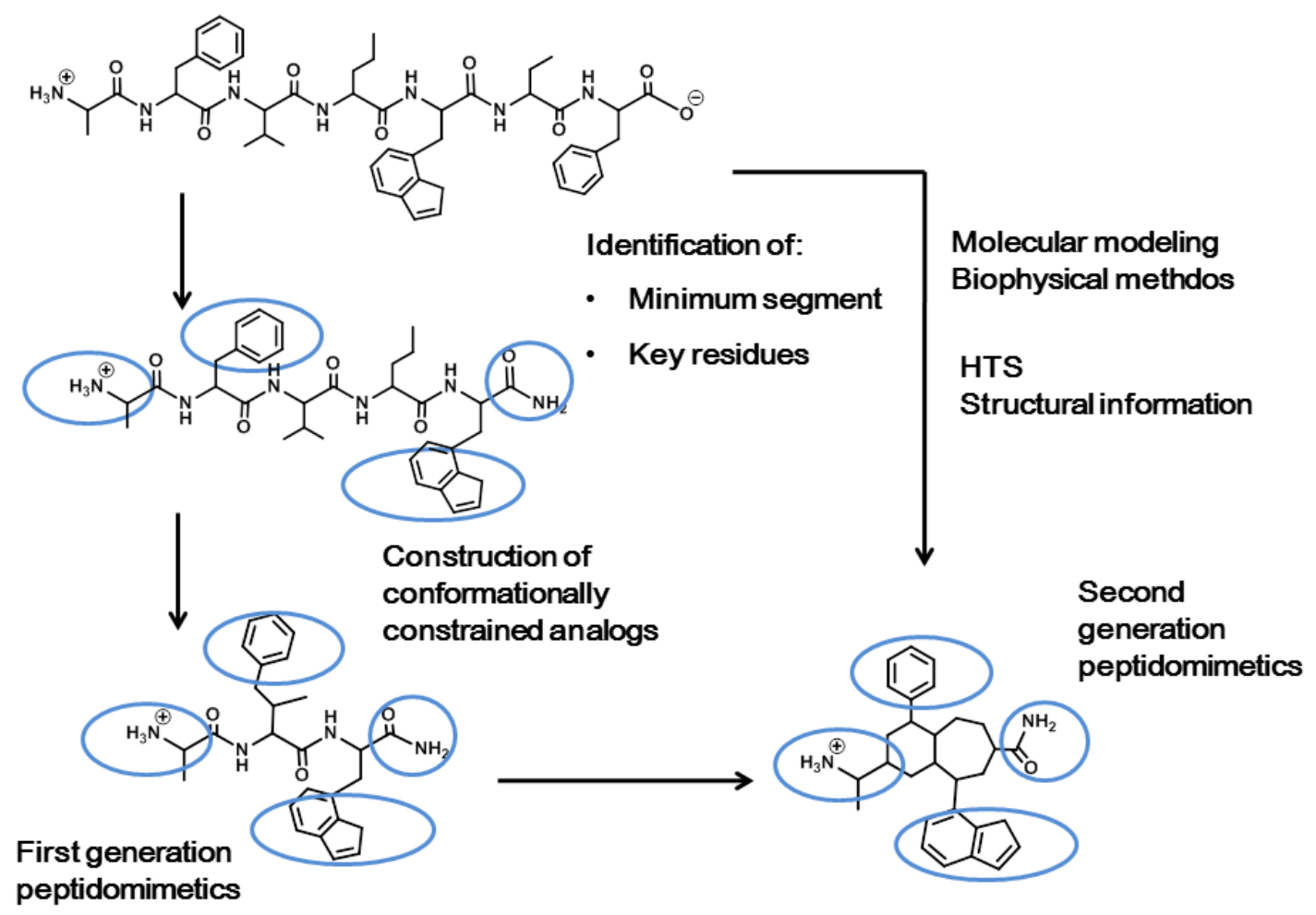


Figure 2. Chemical structures of diverse peptide bond isosteres.<smiles>[R]C(C(C)=O)N(C)C(C)=O</smiles>

1<smiles>[R]C(CC(C)=O)C(C)=O</smiles>

6<smiles>[R]C(NCC)C(C)=O</smiles>

2

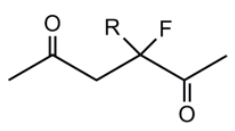

7<smiles>[R]C(NC(C)=S)C(C)=O</smiles>

3

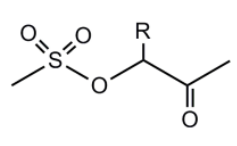

9<smiles>[R]C(OC(C)=S)C(C)=O</smiles>

5<smiles>[R]C(NP([R])(C)=O)C(C)=O</smiles>

10<smiles>[R]C(CC(C)O)C(C)=O</smiles>

15<smiles>[R]C(OP(C)(=O)O)C(C)=O</smiles>

11<smiles>[R]C(SP(C)(=O)O)C(C)=O</smiles>

12<smiles>[R]C(CP(C)(=O)O)C(C)=O</smiles>

13<smiles>[R]C(NC(C)O)C(C)=O</smiles>

14 
Figure 2 (cont.) Chemical structures of diverse peptide bond isosteres.<smiles>[R]C(C(C)=O)C(O)C(C)O</smiles>

16<smiles>[R]C(CC(C)C(F)(F)F)C(C)=O</smiles>

17<smiles>[R]C(CCC)C(C)=O</smiles>

20<smiles>[R]C(C=C(C)F)C(C)=O</smiles>

22<smiles>[R]C(C(C)=O)C(F)=C(C)F</smiles>

23<smiles>[R]C(C=CC)C(C)=O</smiles>

21<smiles>[R]C(OCC)C(C)=O</smiles>

18

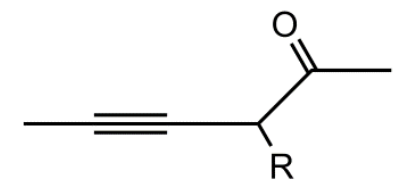

24<smiles>CC(=O)NNC(C)=O</smiles>

25<smiles>CC(=O)NOC(C)=O</smiles>

26<smiles>CC(=O)NC1(C(C)=O)CCC1[Y19]=[V]</smiles>

27<smiles>CC(=O)NC1(C(C)=O)CNC1</smiles>

$\mathrm{n}=0,1,2, \ldots$<smiles>[H][Y19](=[V])[Al]1OCC1(NC(C)=O)C(C)=O</smiles>

29 
Figure 3. Chemical structures of some peptide surrogates and unnatural amino acids.<smiles>[R]C(NC(C)=O)NC(C)=O</smiles>

30<smiles>[R]C(CC(C)=O)NC(C)=O</smiles><smiles>CC(=O)C(C)(C)N(C)C</smiles>

34<smiles>C=C(C(C)=O)N(C)C</smiles>

35<smiles>[R]N(CC(C)=O)C(C)=O</smiles>

31<smiles>CC(=O)C1(N(C)C)CC1C1(C)CC1</smiles>

36 
Figure 4. Diverse schemes to produce cyclic peptides.<smiles>[R]C(=O)C(=O)NCCC([R])C([R])CC</smiles>

$\mathrm{X}=\mathrm{NH}$ $\mathrm{X}=\mathrm{O}$ (depsipepde)

Head-to-tail cyclization<smiles>[X]C(=O)C([R])NNC(=O)C(N)CC</smiles>

$\mathrm{X}=\mathrm{NH}$

$\mathrm{X}=\mathrm{O}$ (depsipeptide)

Side chain to tail cyclization

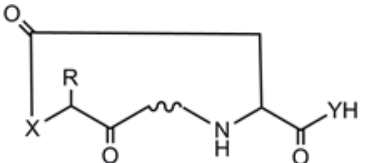

$\mathrm{X}=\mathrm{NH}$ (lactam bridge)

$\mathrm{X}=\mathrm{O}$ (depsipeptide)

Head to side chain cyclization<smiles>[X]CC(N)C(=O)NCC(N)C(N)=O</smiles>

$\mathrm{Y}=\mathrm{NH}$ (amide)

$\mathrm{Y}=\mathrm{OH}($ acid $)$

$\mathrm{X}=\mathrm{S}$-S (disulfide bridge)

$\mathrm{X}=\mathrm{NH}-\mathrm{CO}$ (lactam bridge)

$\mathrm{X}=\mathrm{S}$ (thioether)

$\mathrm{X}=\mathrm{O}-\mathrm{CO}$ (lactone bridge; depsipeptide)

$\mathrm{X}=\mathrm{CH}=\mathrm{CH}$ (alkene bridge)

$\mathrm{X}=\mathrm{CH} \equiv \mathrm{CH}$ (alkyne bridge)

Side chain to side chain cyclization 
Figure 5. Chemical structures of diverse conformationally constrained amino acids.<smiles>COC(=O)C1(NC(=O)C(N)CC(=O)O)CC1</smiles>

37

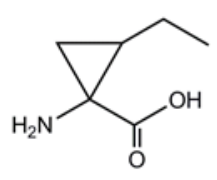

40

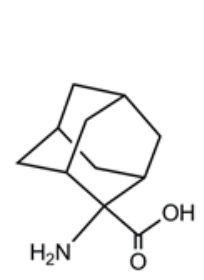

45<smiles>CC(C)CC(OC(=O)C1CCCN1)C(=O)NC1(C(N)=O)CC1</smiles>

38

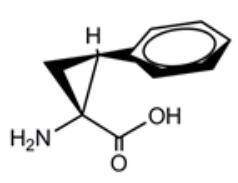

41<smiles>CCOC(=O)C(Cc1ccc(OC)cc1)NC(=O)C1(NC(=O)C(SC(C)=O)C(C)C)CCCC1</smiles>

39

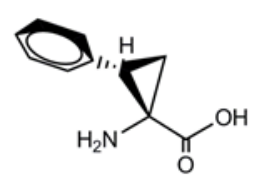

43

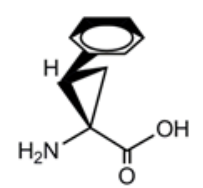

44

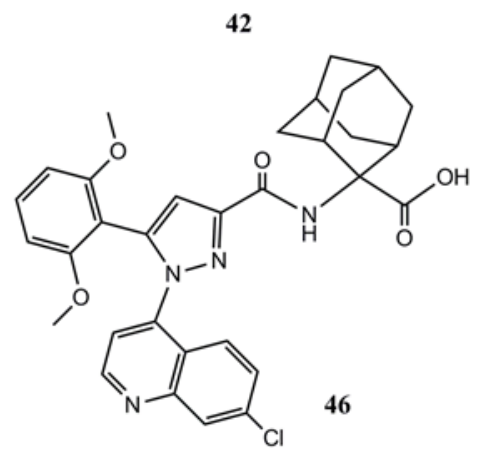

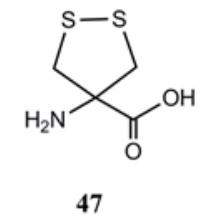


Figure 6. Chemical structures of diverse conformationally constrained amino acids.<smiles>O=C(O)C1CCCN1</smiles>

48<smiles>CC1(C)SCNC1C(=O)O</smiles>

53<smiles>O=C(O)C1CN1</smiles>

49<smiles>O=C(O)C1CCN1</smiles>

50<smiles>O=C(O)C1CCCCN1</smiles>

51<smiles>O=C(O)C1CNCC1c1ccccc1</smiles>

52<smiles>O=C(O)C1Cc2ccccc2N1</smiles>

54<smiles>O=C(O)C1Cc2ccccc2CN1</smiles>

55<smiles>NCCCC(NC(C(=O)O)c1ccccc1)C(=O)C1CCC(C(=O)O)N1</smiles>

56<smiles>CCOC(=O)C(CCc1ccccc1)NC(C)C(=O)N1Cc2ccccc2CC1C(=O)O</smiles>

57<smiles>CC(C)(S)C(N)C(=O)O</smiles>

58<smiles>CC(c1ccccc1)C(N)C(=O)O</smiles>

59<smiles>CC(C)(c1ccccc1)C(N)C(=O)O</smiles>

60 
Figure 7. Chemical structures of diverse dipeptide mimetics.<smiles>CC1(C)SC2C(NC(=O)Cc3ccccc3)C(=O)N2C1C(=O)O</smiles><smiles>CCC(CC)N1CCCC(NC)C1=O</smiles>

64<smiles>[R]C1Cc2ccccc2CN([R8])C1=O</smiles>

72

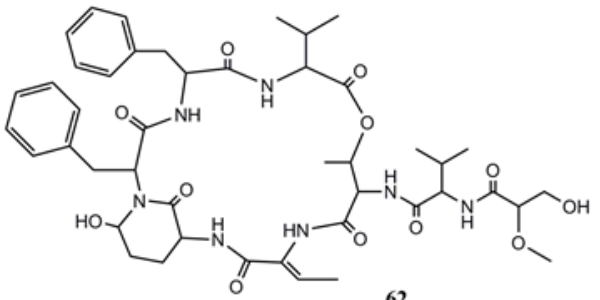<smiles>[R]C1CN([R1])C(=O)CN1[R]</smiles>

65<smiles>CN1CC(=O)N(C)CC1=O</smiles>

66<smiles>[2H]N1C(C)C(=O)N(C)C(=O)C1OCC</smiles>

67<smiles>[R]C1CN([R])CCN([R])C1=O</smiles>

68

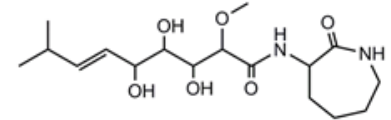

63<smiles>[R3]C1=NC2C=CC=CC2N([R])C1=O</smiles><smiles>[R]C1C[SH]([R3])C2C=CC=CC2N([R])C1=O</smiles><smiles>[R]C(C)C([R])C(=O)N1CCCC1C</smiles><smiles>[R]C1Cc2ccccc2N2CCCC1C2=O</smiles><smiles>[R]C1CC2SCCN2C(=O)C12CCCN2[R]</smiles> 
Figure 8. Chemical structures of diverse $\beta$-hairpin turn scaffolds.

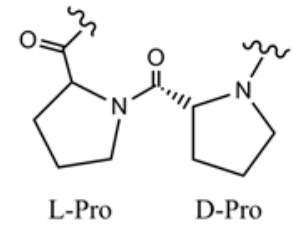

78

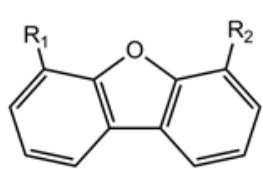

82<smiles>[R]Oc1ccc2ccc(O[R])nc2c1</smiles>

86<smiles>[R]C1NC(=O)C2C([R])C([R])CN2C1=O</smiles>

79

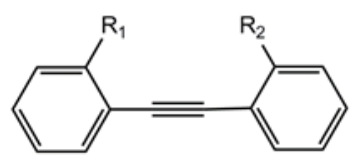

83<smiles>[R]c1ccc(N(C)C(=O)N(C)c2ccc([R])cc2)cc1</smiles>

87

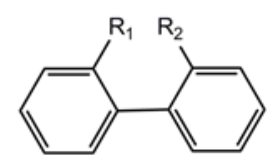

80<smiles>[R]c1cc(C)cc2c1Oc1c([R2])cc(C)cc1S2(=O)=O</smiles>

84<smiles>[R]N(CCCN([R])C(=O)NC)C(=O)NC</smiles>

88<smiles>[R]c1ccccc1-c1cnn(-c2ccccc2[R])n1</smiles>

81<smiles>[R]Oc1ccc2ccc(O[R])cc2c1</smiles>

85<smiles>NCc1ccc(/N=N\c2ccc(C(=O)O)cc2)cc1</smiles>

89 
Figure 9. Chemical structures of diverse $\beta$-strand cyclic peptide mimetics.

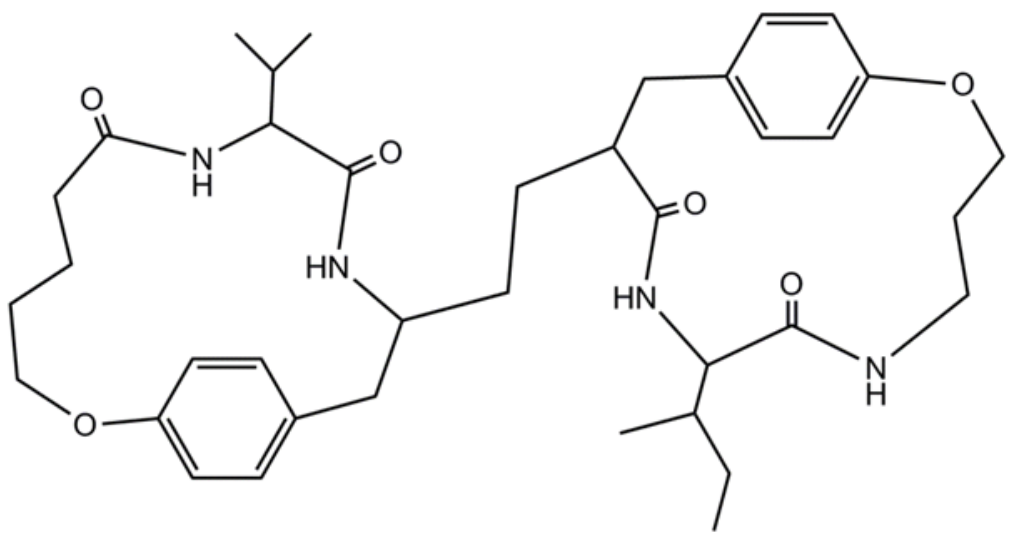

90

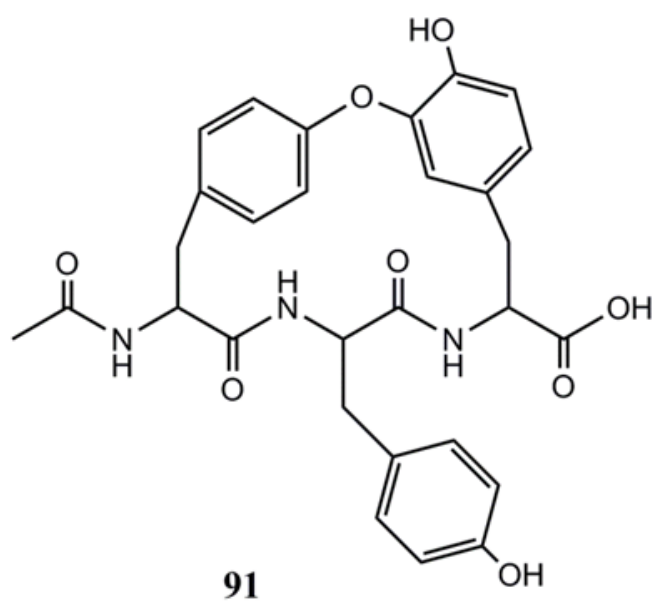<smiles>NC(=O)CC(NC(=O)C(N)Cc1ccc(O)c(Oc2ccc(CC(NC(=O)C(=O)O)C(=O)O)cc2)c1)C(=O)O</smiles>

92 
Figure 10. Chemical structures of diverse $\beta$-strand enhancers and scaffold mimetics.

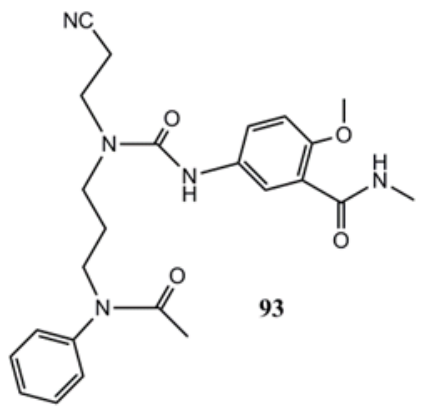<smiles>[R]C(NC1=CC(=O)CN(C(C)=O)C1)C(=O)N1CC(=O)C=C(NC)C1</smiles><smiles>[R]C(NC1=NC(=O)CN(C(C)=O)C1[R])C(=O)N1CC(=O)N=C(NC)C1[R]</smiles>

95
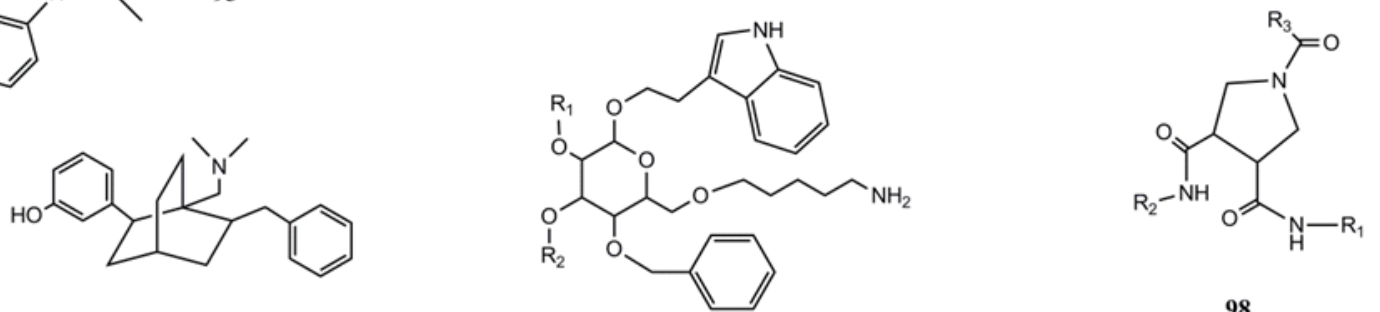

96

97
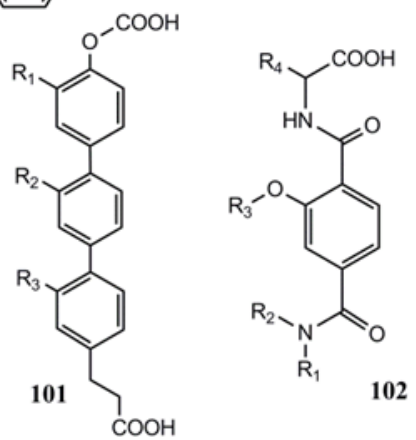

98<smiles>[R]C1=CN([R])C([R])C(=O)N1[R]</smiles>

99<smiles>[R7]Oc1ccc2c(c1)N([R])CCC21C(=O)N([R8])C(=O)N1[R]</smiles>

100

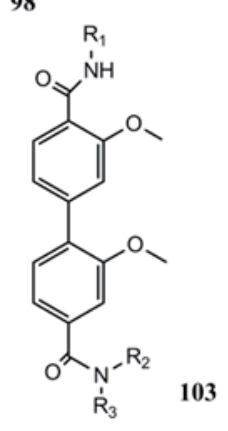


Figure 11. Chemical structures of diverse secondary structure scaffolds.<smiles>CSCCC(NC(=O)c1ccc(NC(=O)C(N)CS)cc1)C(=O)O</smiles>

104<smiles>CSCCC(NC(=O)c1cccc2c(NC(=O)C(N)CS)cccc12)C(=O)O</smiles>

105<smiles>[R]C1CN(c2cccc(N3CC([R])N(C4C=C(C)C=CC4)C3=O)c2)C(=O)N1c1cccc([N+](=O)[O-])c1</smiles>

106

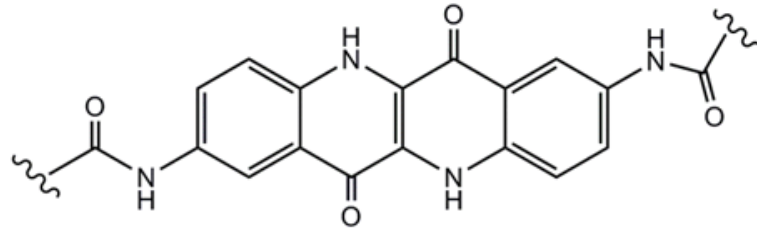

107<smiles>CC(C)NC(C)C1=CC(=O)C(C)(C2=CC(=O)C(C)(C3=CC(=O)C(C)(C(=O)S)N3)N2)N1</smiles>

108<smiles>COc1ccc(NC(=O)C(=O)O)cc1C(=O)NN</smiles>

109<smiles>COc1ccc(NC(=O)C(=O)NCCCC(N)=O)cc1C(=O)NN</smiles>

110<smiles>[Z]Nc1cccc(C(=O)S)c1C#Cc1c(NC(C)C)cccc1C(=O)S</smiles>

111 